\title{
Skilled Movements in Mice Require Inhibition of Corticospinal Axon Collateral Formation in the Spinal Cord by Semaphorin Signaling
}

\author{
ĐZirong Gu, ${ }^{1}$ Masaki Ueno, ${ }^{1,5,6}$ Kelsey Klinefelter, ${ }^{1}$ @Madhulika Mamidi, ${ }^{1}$ ○Takeshi Yagi, ${ }^{4}$ and $\odot$ Yutaka Yoshida ${ }^{1,2,3}$ \\ ${ }^{1}$ Division of Developmental Biology, Cincinnati Children's Hospital Medical Center, Cincinnati, Ohio 45229, ${ }^{2}$ Burke Neurological Institute, White Plains, \\ New York 10605, ${ }^{3}$ Brain and Mind Research Institute, Weill Cornell Medicine, New York, New York 10065, ${ }^{4}$ KOKORO-Biology Group, Laboratories for \\ Integrated Biology, Graduate School of Frontier Biosciences, Osaka University, Suita, Japan, ${ }^{5}$ Department of System Pathology for Neurological Disorders, \\ Brain Research Institute, Niigata University, Niigata, Niigata, 951-8585, Japan, and 'Precursory Research for Embryonic Science and Technology, Japan \\ Science and Technology Agency, Kawaguchi, Saitama, 332-0012, Japan
}

Corticospinal (CS) neurons in layer V of the sensorimotor cortex are essential for voluntary motor control. Those neurons project axons to specific segments along the rostro-caudal axis of the spinal cord, and reach their spinal targets by sending collateral branches interstitially along axon bundles. Currently, little is known how CS axon collaterals are formed in the proper spinal cord regions. Here, we show that the semaphorin3A (Sema3A)-neuropilin-1 (Npn-1) signaling pathway is an essential negative regulator of CS axon collateral formation in the spinal cord from mice of either sex. Sema3A is expressed in the ventral spinal cord, whereas CS neurons express Npn-1, suggesting that Sema3A might prevent CS axons from entering the ventral spinal cord. Indeed, the ectopic expression of Sema3A in the spinal cord in vivo inhibits CS axon collateral formation, whereas Sema3A or Npn-1 mutant mice have ectopic CS axon collateral formation within the ventral spinal cord compared with littermate controls. Finally, $N p n-1$ mutant mice exhibit impaired skilled movements, likely because of aberrantly formed CS connections in the ventral spinal cord. These genetic findings reveal that Sema3A-Npn-1 signaling-mediated inhibition of CS axon collateral formation is critical for proper CS circuit formation and the ability to perform skilled motor behaviors.

Key words: axon collateral; axon guidance; corticospinal circuits; neuropilin; semaphorin; spinal cord

Significance Statement

CS neurons project axons to the spinal cord to control skilled movements in mammals. Previous studies revealed some of the molecular mechanisms underlying different phases of CS circuit development such as initial axon guidance in the brain, and midline crossing in the brainstem and spinal cord. However, the molecular mechanisms underlying CS axon collateral formation in the spinal gray matter has remained obscure. In this study, using in vivo gain-of- and loss-of-function experiments, we show that Sema3A-Npn-1 signaling functions to inhibit CS axon collateral formation in the ventral spinal cord, allowing for the development of proper skilled movements in mice.

\section{Introduction}

Proper formation of corticospinal (CS) circuits is essential for skilled motor behaviors in mammals (Porter and Lemon, 1993;
Martin, 2005). During development, CS axons extend from layer $\mathrm{V}$ of the cerebral cortex down through the cerebral peduncles and brainstem and along the rostrocaudal axis of the spinal cord (Canty and Murphy, 2008). After the CS axons reach appropriate segmental levels, they send collaterals from their main axon bundles to connect to motor neurons, either directly (in primates only) or indirectly via interneurons (in all mammals; Porter and Lemon, 1993; Lemon, 2008), thereby forming the circuits connecting the motor cortex to the muscles.

\footnotetext{
Received Nov. 2, 2018; revised Sept. 6, 2019; accepted Sept. 11, 2019.

Author contributions: Z.G. and Y.Y. designed research; Z.G., M.U., K.K., and M.M. performed research; Z.G. analyzed data; T.Y. contributed unpublished reagents/analytic tools; Z.G. and Y.Y. wrote the paper.

This work was supported by Grants from NINDS (NS093002 and NS100772) to Y.Y. We thank E. Giraudo for providing AAV-Sema3A, and K. Gaintonde for mouse maintenance.

The authors declare no competing financial interests.

Correspondence should be addressed to Yutaka Yoshida at yoy4001@med.cornell.edu.

Z. Gu's present address: Zuckerman Mind Brain Behavior Institute, Columbia University, New York, NY 10027.
} 
Some progress has been made in investigating the molecular mechanisms of the initial axon guidance of CS neurons (CSNs) during development (Canty and Murphy, 2008). For example, netrin signaling via DCC and Unc5 receptors and ephrin signaling have been shown to be involved in the decision of CS axons to cross the midline at the junction of the brainstem (Kullander et al., 2001; Finger et al., 2002; Wegmeyer et al., 2007; Asante et al., 2010; Paixão et al., 2013). Class 6 semaphorins also control the midline crossing of CS axons in the brainstem (Faulkner et al., 2008; Rünker et al., 2008). Ryk-mediated Wnt signaling plays a role in posterior-directed CS axon growth in white matter (Liu et al., 2012). Moreover, repellent guidance molecules such as semaphorin3A (Sema3A) and semaphorin3C (Sema3C) have also been implicated in axon guidance of cortical neurons (including CSNs) using in vitro explant cultures (Bagnard et al., 1998). Interestingly, L1 Ig superfamily adhesion molecule (L1CAM) binds to neuropilin-1 (Npn-1), which is a receptor for class 3 semaphorins (Castellani et al., 2000, 2002), and L1 mutant mice show defects in fasciculation and midline crossing of CS axons (Cohen et al., 1998; Jakeman et al., 2006). In contrast, the in vivo roles of Sema3A signaling in axonal trajectory of CSNs is less clear, as Sema3A mutant mice did not show any defects in elongation, collateralization, fasciculation, or path-finding of CS axons (Sibbe et al., 2007).

Axon bundles, such as the CS axons in the spinal white matter, send collaterals to form connections with appropriate target neurons (Porter and Lemon, 1993; Canty and Murphy, 2008; Lemon, 2008). Therefore, the proper formation of axon collaterals from the main axon bundles is an essential step toward the development of complex motor circuits (Kalil and Dent, 2014). CS axons are a model system for studying axon collateral formation, because CS axons innervate their spinal targets by extending collateral branches interstitially along their entire axon length in the spinal gray matter (Porter and Lemon, 1993; Canty and Murphy, 2008; Lemon, 2008). Using slice cultures from neonatal mice, a previous study showed that collateral branching activity is spatially restricted to specific portions of the CS axon within a brief, temporally-restricted window (Bastmeyer and O'Leary, 1996). It has also been shown that an individual CS axon has multiple sites of branching activity, and many of those collateral branches are transient (Bastmeyer and O'Leary, 1996). Together, these observations suggest that CS axon collaterals are precisely regulated during development. Although the negative control of CS axon collateral formation is likely critical for the establishment of mature patterns of axonal arborization and connectivity, the mechanisms suppressing CS axon collateral formation in the spinal cord remain obscure.

Here we assess the role of Sema3A-Npn-1 signaling in the development of CS circuits in mice. In vivo Sema3A gain-of-function experiments demonstrated that Sema3A-Npn-1 signaling is sufficient to suppress CS axon collateral formation in the spinal cord. Conversely, in Sema3A mutant mice and forebrain-specific Npn-1deficient mice, we found that CS axons exhibit excessive collateral formation. Npn-1-deficient mice exhibited impairments in skilled movements. Therefore, this study identified Sema3A-Npn-1 signaling as an essential negative regulator of CS axon collateral formation within the spinal cord in vivo, which is critical for the establishment and functioning of appropriate CS circuits in mice.

\section{Materials and Methods}

\section{Mouse lines}

The following mouse strains were used in this study: Emx1-Cre (Gorski et al., 2002), CAG-CAT-eGFP (ccGFP) (Nakamura et al., 2006), Npn-1 fl/fl (Gu et al., 2003), and Sema3 $A^{-/-}$(Taniguchi et al., 1997). Mice were maintained on a mixed background. Mice of either sex were used in the study. All animals were treated according to institutional and National Institutes of Health guidelines, with the approval of the Institutional Animal Care and Use Committee at Cincinnati Children's Hospital Medical Center and Burke Neurological Institute/Weill Cornell Medicine.

\section{In situ hybridization}

Brains and spinal cords were fixed by submersion in $4 \%(\mathrm{w} / \mathrm{v})$ paraformaldehyde (PFA)/phosphate-buffered saline (PBS) overnight at $4^{\circ} \mathrm{C}$. RNA in situ hybridizations were performed on 16-20 $\mu \mathrm{m}$ cryosections according to standard protocols. T7 or Sp6 RNA polymerase (Roche) was used to synthesize antisense digoxigenin-labeled probes for in situ hybridizations as previously described (Schaeren-Wiemers and GerfinMoser, 1993).

\section{Immunohistochemistry and imaging}

Perfusion fixation (ice-cold PBS followed by 4\% PFA) was used to harvest brains and spinal cords. Upon dissection, the brain and spinal cord were fixed overnight at $4^{\circ} \mathrm{C}$. Brains and spinal cords were cryoprotected by immersion in $30 \%$ sucrose/PBS for $48 \mathrm{~h}$ and sectioned using a cryostat at 50 and $80 \mu \mathrm{m}$ thickness, respectively. Free-floating immunohistochemistry was performed by incubating brain and spinal cord sections with primary antibodies overnight at room temperature, then incubating with fluorophore-conjugated secondary antibodies for $4 \mathrm{~h}$ at room temperature. Sections were mounted with VECTASHIELD Mounting Media (Vector Laboratories) and coverslipped for imaging. Confocal images were taken with a Nikon A1R GaAsP or Carl Zeiss LSM 510 LaserScanning Confocal Microscope. The following primary antibodies were used in this study: chicken anti-eGFP (1:2000; Abcam); rabbit antiDsRed (1:1000; Clontech); goat anti-mCherry (1:2000; Biorbyt); goat anti-LacZ (1:2000; Biogenesis); and guinea pig anti-vGlut2 (1:5000; Millipore). The fluorophore-conjugated secondary antibodies were obtained from Jackson ImmunoResearch and Invitrogen. For biotinylated dextran amine (BDA) staining, $20-\mu \mathrm{m}$-thick spinal cord sections were incubated in $0.3 \%$ Triton X-100/PBS for $4 \mathrm{~h}$, followed by incubation with AlexaFluor 568 streptavidin (1:400; Invitrogen) for $2 \mathrm{~h}$ at room temperature.

\section{Surgery and viral injections}

Overexpression of Sema3A in the lumbar spinal cord of $\mathrm{PO}$ mice. Mice were anesthetized with isoflurane during surgery and injections. A laminectomy was performed at the L1-L4 lumbar spinal cord region of P0 Emx1Cre; ccGFP mice to expose the lumbar spinal cord. A fine glass capillary loaded with $400 \mathrm{nl}$ of adeno-associated virus (AAV) 8 expressing Sema3A and $L a c Z$ (an equal mixture of $A A V 8-C M V$-Sema $3 A / 2 \times 10^{12} \mathrm{GC} / \mathrm{ml}$ and $A A V 8-C M V-L a c Z / 2 \times 10^{12} \mathrm{GC} / \mathrm{ml}$, gifts from Dr. Enrico Giraudo from the University of Torino, Italy; Maione et al., 2009) was inserted into the lumbar spinal cord using the following coordinates: $0 \mathrm{~mm}$ lateral to the midline, at a depth of $0.8 \mathrm{~mm}$. Two injections ( $400 \mathrm{nl}$ each) of the virus mixture were delivered to the $\mathrm{L} 2$ and $\mathrm{L} 4$ lumbar spinal cord region. Mice injected with $A A V 8-C M V-L a c Z / 1 \times 10^{12} \mathrm{GC} / \mathrm{ml}$ were used as controls. Spinal cords were collected at P14 (see Fig. 2)

Anterograde axon tracing with AAV. AAV1-CAG-tdTomato $\left(1 \times 10^{11}\right.$ $\mathrm{GC} / \mathrm{ml}, 200 \mathrm{nl} /$ injection; Penn Vector Core) was injected into the left hemisphere of mice at $\mathrm{P} 4$ using the following coordinates: $1 \mathrm{~mm}$ rostral to bregma, $0.7 \mathrm{~mm}$ lateral to the midline, at a depth of $0.4 \mathrm{~mm}$. Spinal cords and brains were collected from 6-week-old mice (see Figs. 5, 6, 8).

Anterograde axon tracing with BDA. BDA (MW: 10,000; Invitrogen; $10 \%$ in PBS) was injected into the cerebral cortex at 6 weeks using the following coordinates: sensory CS tract (CST), $0.5 \mathrm{~mm}$ rostral to bregma and $2.5 \mathrm{~mm}$ lateral to the midline, $0.5 \mathrm{~mm}$ caudal and $2.5 \mathrm{~mm}$ lateral, at a depth of $0.5 \mathrm{~mm}$ (Ueno et al., 2018). Spinal cords and brains were collected 2 weeks after injections (see Fig. 9).

\section{Behavioral tests}

Grip strength analysis. Forelimb and hindlimb grip strengths of mice were measured using a grip strength meter from Columbus Instruments as previously described (Gu et al., 2017b). Average force was calculated for each mouse based on three trials and expressed as grams-force ( $\mathrm{gf} ; 1 \mathrm{gf}=$ $9.8 \times 10^{-3}$ newton). 


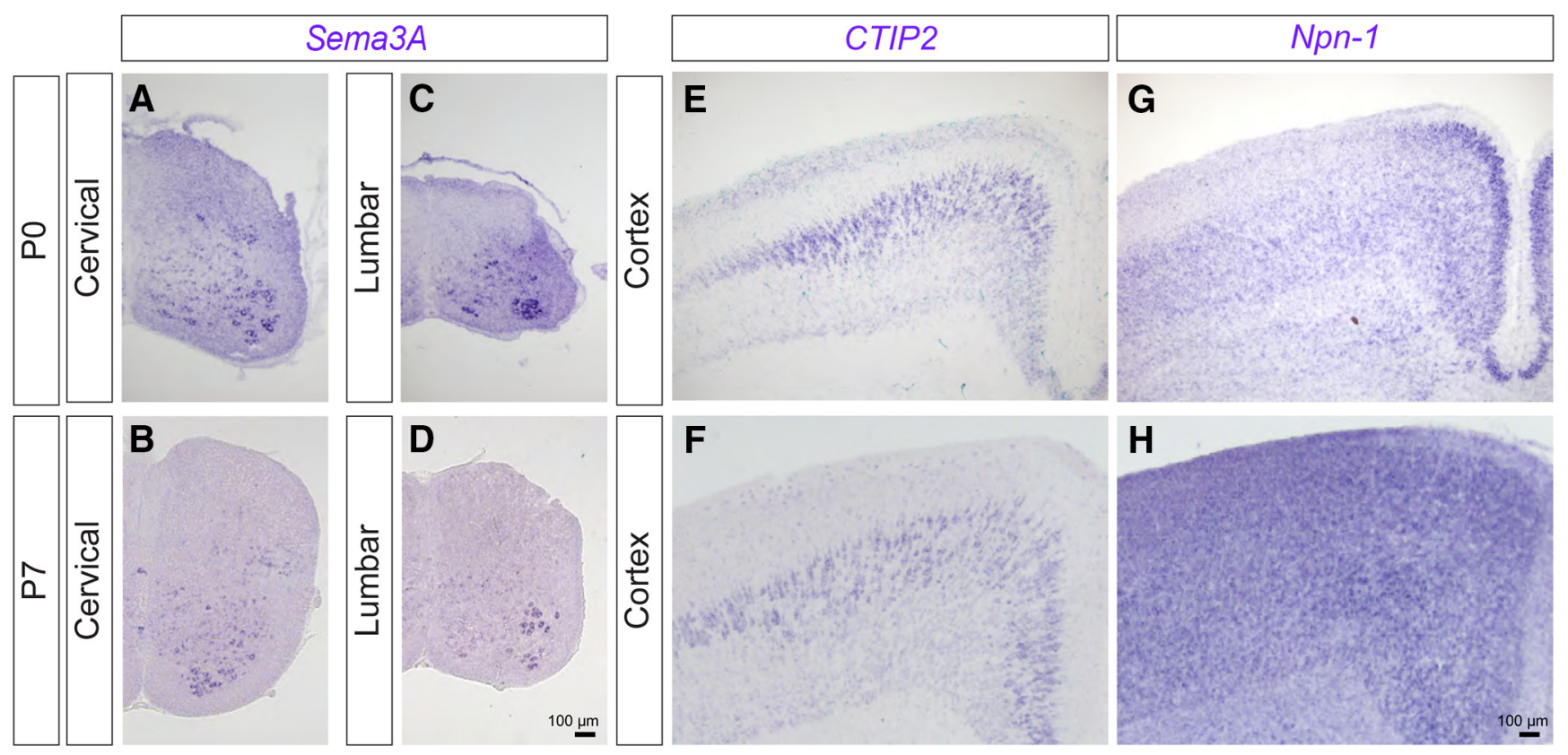

Figure 1. Expression of Sema3A and Npn-1 in the spinal cord and cortex. $\boldsymbol{A}-\boldsymbol{H}$, In situ hybridization of Sema3A $(\boldsymbol{A}-\boldsymbol{D})$, CTIP2 $(\boldsymbol{E}, \boldsymbol{F})$, and Npn-1 $(\boldsymbol{G}, \boldsymbol{H})$ in the cervical spinal cord $(\boldsymbol{A}, \boldsymbol{B})$, the lumbar spinal cord $(\boldsymbol{C}, \boldsymbol{D})$, and the cortex $(\boldsymbol{E}-\boldsymbol{H})$ at $\mathrm{PO}(\boldsymbol{A}, \boldsymbol{C}, \boldsymbol{E}, \boldsymbol{G})$ and $\mathrm{P} 7(\boldsymbol{B}, \boldsymbol{D}, \boldsymbol{F}, \boldsymbol{H})$. Scale bars, $100 \mu \mathrm{m}$.

Single-pellet reaching test. We assessed the performance of 7-week-old mice in a single pellet reaching test as previously described, with minor modifications (Xu et al., 2009). Briefly, mice were food-restricted to maintain $90 \%$ of their free-feeding weight before the training. We determined the preferred limb for each mouse during the shaping phase (2-4 d), which was followed by a $7 \mathrm{~d}$ training protocol. We recorded 30 reaches from each mouse per day during training. Only when the mouse successfully retrieved the seed and put it into its mouth was the attempt considered a success.

Accelerating rotarod. the accelerating rotarod was used to assess motor coordination and motor learning (Med Associates). Mice were placed on a $3 \mathrm{~cm}$ diameter rod with an initial rotation of $4 \mathrm{rpm}$ that accelerated to $40 \mathrm{rpm}$ over $5 \mathrm{~min}$. Mice were tested for tumble latency (time before falling off the rod) in eight trials over 2 consecutive days as described before (Daily et al., 2011).

Grid-walking test. the grid-walking test was performed as described previously (Starkey et al., 2005; Gu et al., 2017b). Briefly, mice were placed on a square wire grid $(15 \times 15 \mathrm{~mm}$ grid squares $)$ and allowed to freely explore for $3 \mathrm{~min}$. Sessions were videotaped and scored for the percentage of forelimb foot-slips (when paws missed a rung or slipped off a rung) in the first 50 steps taken with forepaws.

Beam-walking test. the beam-walking test was performed as previously described (Gu et al., 2017b). Beams with a flat surface of 16, 8, and $4 \mathrm{~mm}$ width were used in this test. Performance on the beam was quantified by measuring the time required for each mouse to traverse the beam and the number of foot-slips that occurred in the process. Sessions were videotaped and scored for the percentage of foot-slips in the first 50 hindlimb steps.

\section{Quantification and data analysis}

Quantification of CS axon density/arborization surface. ImageJ (NIH) was used to measure CS axon density labeled by fluorescent proteins. The values from mutant mice or experimental groups were normalized to those of controls. Data are expressed as relative arborization surface. Three to five spinal cord sections were quantified for each animal.

Quantification of the number of CS axon collaterals. CS axon collaterals in the lumbar spinal cord labeled in P6 Emx1-Cre; ccGFP mice were divided into three zones: zone I (dorsally projecting population), zone II (medially projecting population), and zone III (ventrally projecting population). The number of CS axon collaterals in each zone was counted. Three to five spinal cord sections were quantified for each mouse.
Quantification of BDA-labeled CS axon density. Images of 12 sections in the cervical (C4-C7) spinal cord were acquired and the distribution of BDA-positive CS axons were analyzed with ImageJ software (NIH). The percentages in the dorsal (lamina $\mathrm{I} \sim \mathrm{IV})$, medial $(\mathrm{V}, \mathrm{VI})$, and ventral spinal gray matter $(\mathrm{VII} \sim \mathrm{X})$ were quantified.

\section{Statistics}

The results are expressed as the mean \pm SEM. Two-way repeatedmeasures ANOVAs were used for Figure 10, $C$ and $E$ (followed by post hoc comparisons). One-way ANOVA followed by Tukey's test was used for Figure $9 C$. Student's $t$ tests were used for other statistical analyses. Error bars indicate the SEM. Significance levels are indicated as follows: ${ }^{\star} p<$ $0.05,{ }^{* *} p<0.01,{ }^{* * *} p<0.001$.

\section{Results}

\section{Expression of Sema3A and Npn-1 in the developing spinal cord and cortex}

To determine whether semaphorins, a large family of repellent molecules, regulate CS axon collateral formation in the spinal cord during development, we first examined the expression patterns of secreted Sema3A-3F in spinal cords of postnatal day $(\mathrm{P}) 0$ and $\mathrm{P} 7$ mice. $\mathrm{P} 0$ and $\mathrm{P} 7$ are key developmental stages in which CS axon collaterals are actively innervating the cervical and lumbar spinal cord, respectively. We observed that Sema3A was selectively expressed in medial and ventral regions of the cervical and lumbar spinal cord in both $\mathrm{P} 0$ and $\mathrm{P} 7$ wild-type mice (Fig. 1A-D).

Previous studies showed that repellent molecules, such as slits and semaphorins in the ventral spinal cord, prevent sensory axons in the dorsal root ganglia from innervating the ventral spinal cord during embryogenesis (Behar et al., 1996; Kitsukawa et al., 1997; Taniguchi et al., 1997; Gu et al., 2003; Yaron et al., 2005). Similarly, Sema3A expressed in the ventral spinal cord in early postnatal stages may inhibit ventral projections of CSNs. Therefore, we examined the early postnatal expression of the Sema3A receptor, Npn-1 (Raper, 2000), in the sensorimotor cortex; the part of the brain in which CSNs originate. Indeed, Npn-1 was expressed in the sensorimotor cortex at P7 (Fig. 1E-H). Thus, 


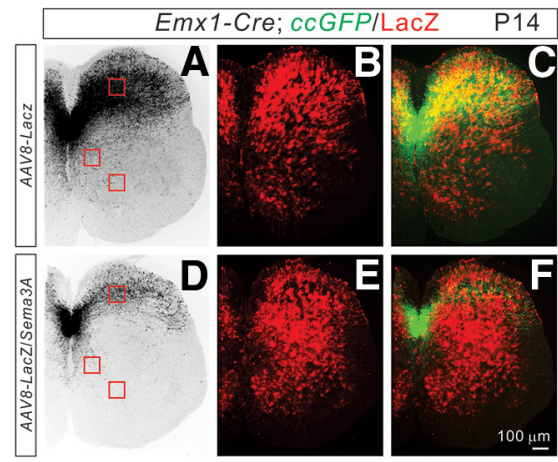

S

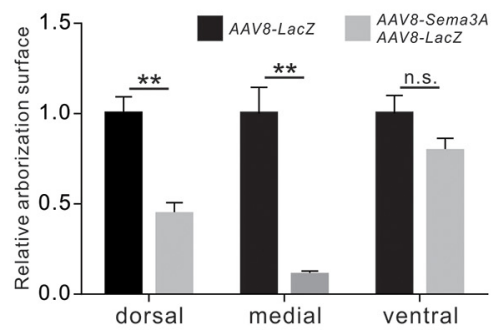

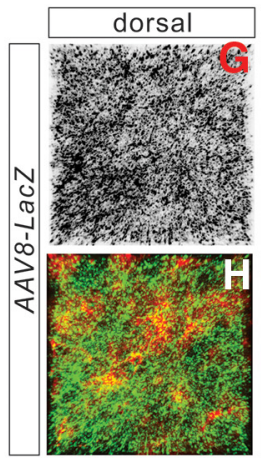
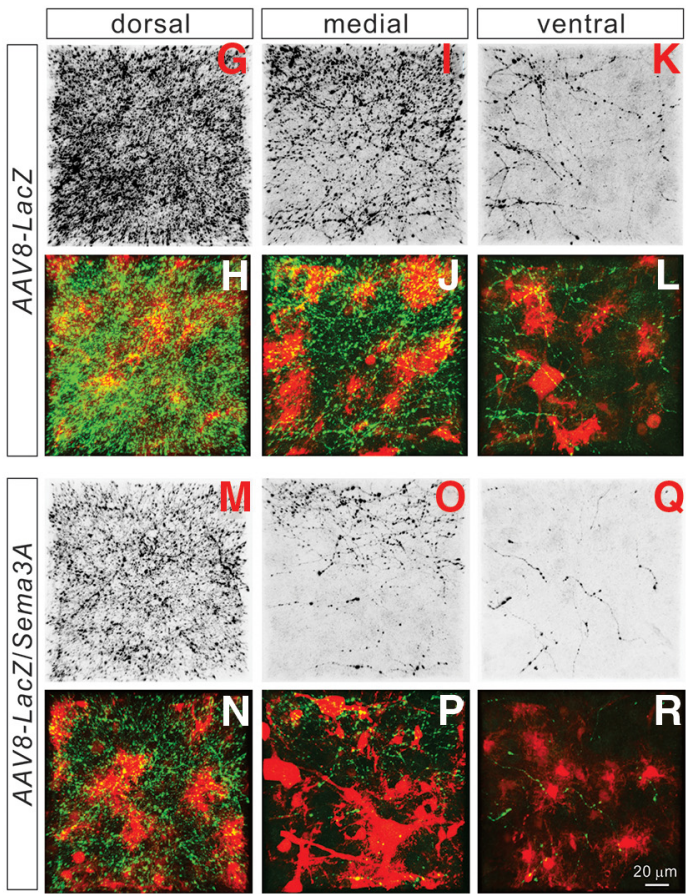

Figure 2. Sema3A negatively regulates CS collateral formation in vivo. $\boldsymbol{A}-\boldsymbol{R}$, Immunostaining of P14 lumbar spinal cord sections from AAV8-LacZ injected (A-C; control) mice and AAV8-LacZ) Sema3A injected mice $(\boldsymbol{D}-\boldsymbol{F})$ using antibodies targeting GFP (green) and LacZ (red). Regions with a high-power view are indicated by red squares. $\mathbf{G}-\boldsymbol{R}$, High-power views of boxed areas from AAV8-LacZ-injected ( $\mathbf{G}-\mathbf{L}$; control) and AAV8-LacZ/Sema3A-injected (M-R) mice. S, Quantification of axon collateral intensities, showing significant reductions of axon collaterals in AAV8-LacZ/ Sema3A-injected mice compared with AAV8-LacZ-injected mice in the dorsal ( $p=0.0023)$ and medial ( $p=0.0041)$ but not ventral $(p=0.2642)$ regions of the lumbar spinal cord. Scale bars: $\boldsymbol{F}$, $100 \mu \mathrm{m} ; \boldsymbol{R}, 20 \mu \mathrm{m} .{ }^{* *} P<0.01$, n.s. $=$ not significant.

Sema3A and Npn-1 are expressed by spinal cord neurons and CSNs, respectively, suggesting that their repellent interactions may inhibit the formation of CS axon collaterals in the ventral spinal cord during development.

\section{Ectopic expression of Sema3A in vivo negatively regulates CS} axon density in the spinal cord

To determine the in vivo role of Sema3A-Npn-1 signaling in CS axon collateral formation in the spinal cord, we used a previously developed AAV vector (AAV8-Sema3A; Maione et al., 2009) to ectopically express Sema3A in the spinal cord of postnatal mice. To visualize CS axon collaterals, Emxl-Cre mice were crossed with a conditional GFP reporter mouse line (Emx1-Cre; ccGFP) (Gorski et al., 2002; Bareyre et al., 2005; Nakamura et al., 2006). $\mathrm{GFP}^{+} \mathrm{CS}$ axon collaterals were observed in the lumbar spinal cord of P14 Emx1-Cre; ccGFP mice. The majority of these GFP ${ }^{+}$ axon collaterals were confined to the dorsal spinal cord, with only a few collaterals localized to the medial and ventral spinal cord (Fig. 2A-C). AAV8-Sema3A and AAV8-LacZ viruses were then coinjected into the $\mathrm{L} 2$ and $\mathrm{L} 4$ regions of the lumbar spinal cord of P0 Emx1-Cre; ccGFP mice. The spread of AAV8 infection was assessed by LacZ immunoreactivity which was detected throughout the lumbar (L2-L4) spinal cord (Fig. 2D-F; data not shown). Emx1-Cre; $c c G F P$ mice that received only injections of AAV8$L a c Z$ were used as controls (Fig. $2 A-C$ ). We observed significant reductions in CS axon collaterals in the dorsal $(p=0.0023, t$ test $)$ and medial $(p=0.0041)$ regions of the lumbar spinal cord in mice injected with AAV8-Sema3A/AAV8-LacZ viruses (Fig. $2 M-S ; n=4$ ) compared with control mice (Figs. $2 G-L, S ; n=5$ ). No significant reductions were observed in the ventral horn of the lumbar spinal cord in AAV8-Sema3A/AAV8-LacZ-injected mice (Fig. $2 K, L, Q-S ; p=0.2642$ ), consistent with the observation that endogenous expression of Sema3A was enriched in the ventral spinal cord (Fig. 1A-D). Collectively, our results demonstrate that elevated expression of Sema3A is sufficient to reduce axon collateral formation of CSNs in the medial and dorsal spinal cord.

No obvious defects in the elongation of CS axons in the dorsal funiculus or in branch initiation of CS axons in $\mathrm{Npn-1}^{\mathrm{flffl} \text {; }}$

\section{Emx1-Cre mice}

To examine how CS axon collaterals form in the spinal cord in the absence of the Sema3A receptor, Npn-1, we examined various aspects of CS circuit formation in Npn-1 $1^{f l f l}$; Emxl-Cre; ccGFP mice in which $N p n-1$ is deleted in the cortex. First, we assessed how deletion of Npn-1 affects the early stages of circuit development, including initial axon guidance, midline crossing, descent in the dorsal funiculus, and initial branch formation of CS axons within the lumbar spinal gray matter. At P10, control $\left(\mathrm{Npn}-1^{f l /+}\right.$; Emx1-Cre, $n=5)$ and Npn-1-deleted mice (Npn-1 ${ }^{f l / f} ;$ Emx1-Cre, $n=7$ ) showed no obvious differences in the overall morphology or trajectory of CS tracts (Fig. $3 A, B$ ). The dorsal turning of the CS tract at the pyramidal decussation also appeared to be normal in $N p n-1^{f l / f l}$; Emx1-Cre mice (Fig. $3 A, B$ ), consistent with a previous study that suggested Npn-1 was not required for the midline crossing of the CS tract in the brainstem (Faulkner et al., 2008).

Second, to compare the descent of CS axons within the dorsal funiculus of the spinal cord between $N p n-1^{f l / f}$; Emx1-Cre mice and controls, we examined the descending CS axons at P4; the stage at which CS axons are just arriving at the rostral part of the lumbar spinal cord (Canty and Murphy, 2008). No marked differences were observed in the projections of CS axons to the lumbar spinal cord of $N p n-1^{f l f f l} ;$ Emxl-Cre mice compared with control mice, with axons in both groups reaching the L1 region and terminating before L2 $\left(\mathrm{Npn} \mathrm{-}^{\mathrm{fl} / \mathrm{fl}}\right.$; Emxl-Cre mice, $n=5 ; \mathrm{Npn-1} \mathrm{fl}^{\mathrm{fl+}} ;$ Emxl-Cre, $n=6$; Fig. $3 C-N)$. Overall, the descent of CS axons appears to be normal in $\mathrm{Npn}$-1-deleted $\left(\mathrm{Npn}-\mathrm{f}^{f l / f} ;\right.$ Emx 1 -Cre $)$ mice. 
A

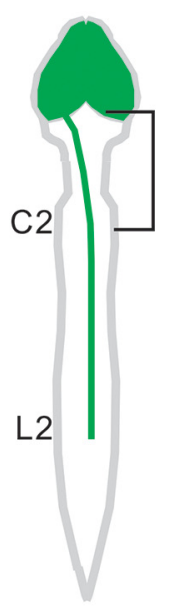

B
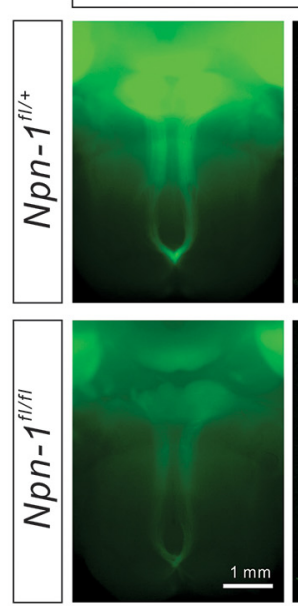
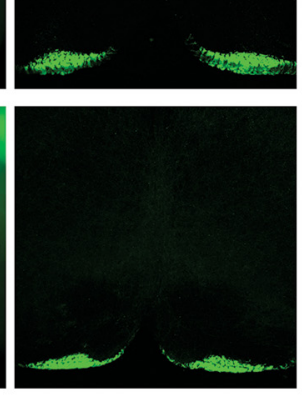

Emx1-Cre; ccGFP
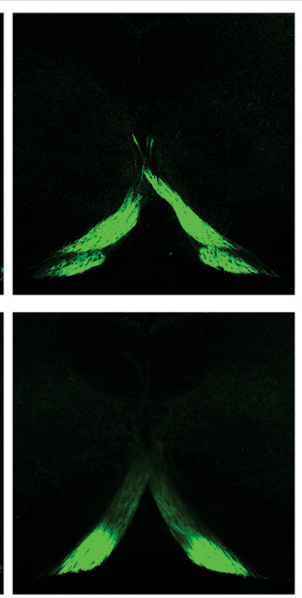

\section{$\mathrm{P} 10$}
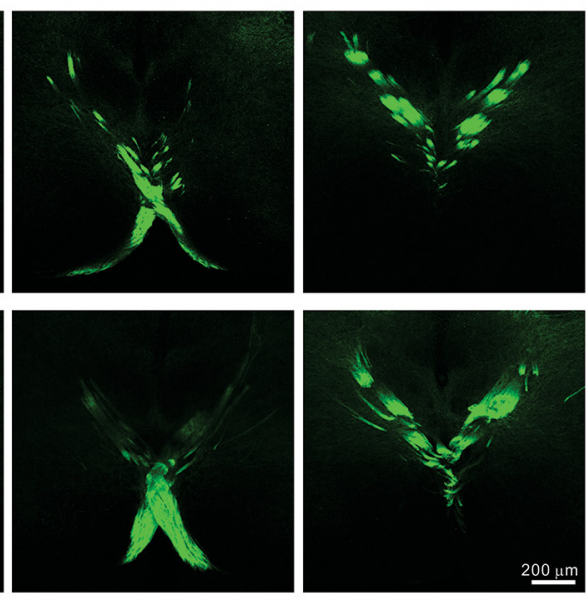

Emx1-Cre; ccGFP P4

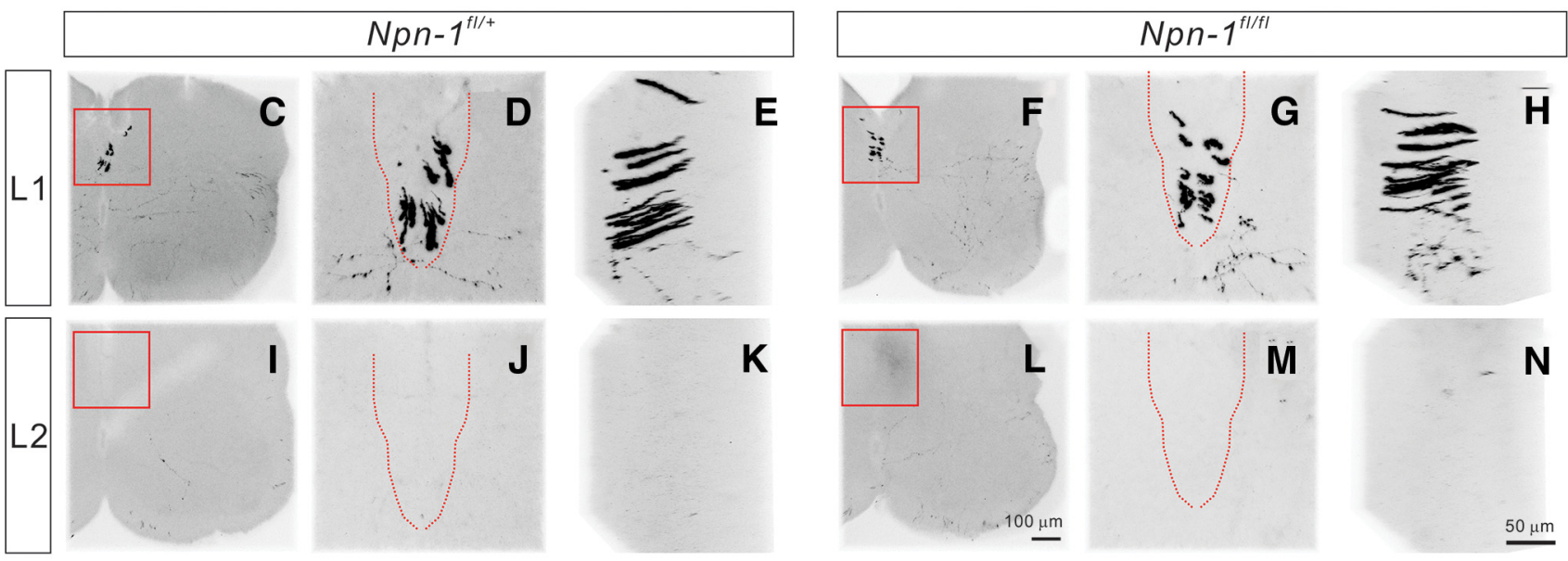

0

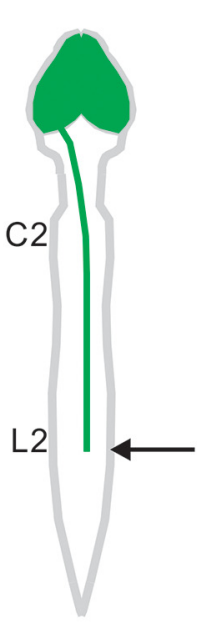

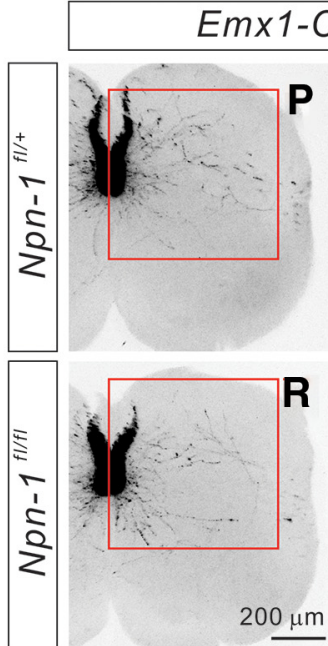

T

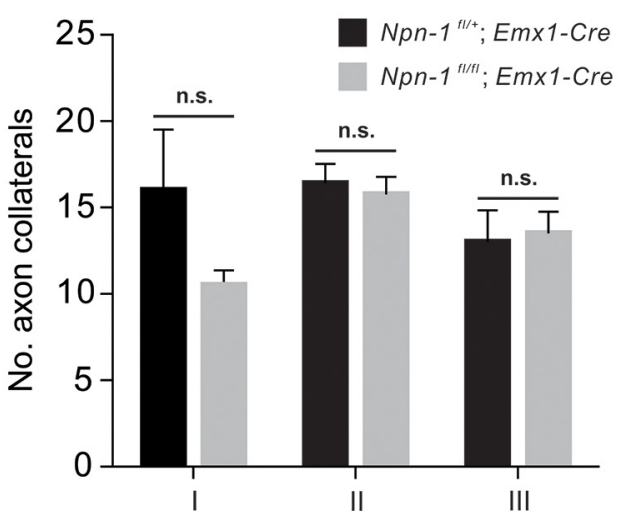

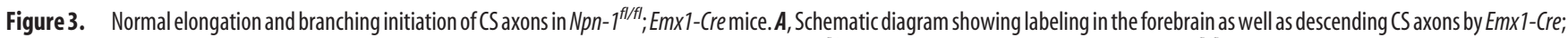

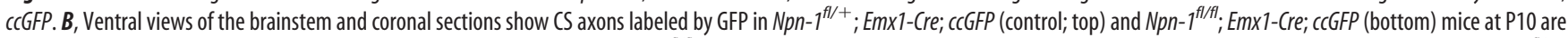

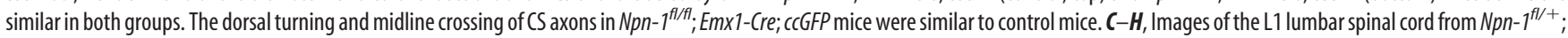

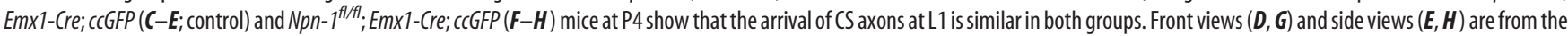

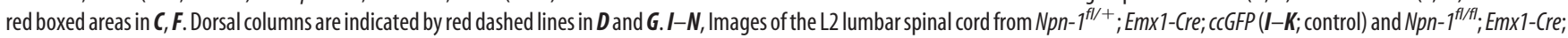
CCGFP $(\boldsymbol{F}-\boldsymbol{H})$ mice at $\mathrm{P} 4$ show the absence of $C S$ axons at $\mathrm{L} 2$ in both groups. Front views $(\boldsymbol{J}, \boldsymbol{M})$ and side views $(\boldsymbol{K}, \boldsymbol{N})$ are from the red, boxed areas in $/$ and $\boldsymbol{L}$. Dorsal columns are indicated by red dashed lines in $(\boldsymbol{J}, \boldsymbol{M}) . \mathbf{O}$, Schematic diagram showing labeling in the forebrain as well as descending (S axons by Emx1-Cre; CCGFPat P6. CSNs begin to send out primary axon shafts at this stage. $\boldsymbol{P}-\mathbf{S}$, Images

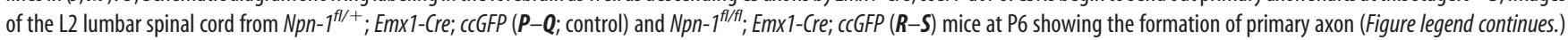


We then determined whether deletion of $N p n-1$ would affect the initiation of CS axon collaterals from primary axon shafts to the spinal gray matter. After descending, each CS axon exits the dorsal column at a discrete location along the spinal cord to make topographically-specific connections with target neurons in the spinal gray matter. This is accomplished by the formation of subsequent collateral branches from the primary axon shaft. We quantified the number of primary axon shafts in the lumbar spinal cord of P6 control (Npn-1 $1^{f l /+}$; Emx1-Cre; ccGFP, $\left.n=5\right)$ and $N p n$-1-deleted mice (Npn-1 $\left.{ }^{f l f l} ; E m \times 1-C r e ; c c G F P, n=4\right)$. In control Npn-1 ${ }^{f l+}$; Emx1-Cre; ccGFP mice, CS axons arrived at the lumbar spinal cord at $\mathrm{P} 4$ and sent out collaterals to innervate the spinal gray matter $\sim$ P6 (Fig. $3 C, P$ ). To quantify the number of primary axon shafts, collaterals were divided into three groups based on the orientation of their projections ( $D$, dorsal; $M$, medial; V, ventral; Fig. $3 C-S$ ). We did not find any obvious changes in any of the projecting CS axon collateral groups in $N p n-1^{f l f l}$; Emx1-Cre; ccGFP mice compared with controls (Fig. 3T), indicating that Npn-1 is largely unnecessary for initial axon collateral formation. These results demonstrate that Sema3A-Npn-1 signaling is unlikely to be required for initial axon guidance, descent, or branch initiation of CS axons.

\section{Npn-1 ${ }^{f l f f}$; Emx1-Cre mice display exuberant CS axon collateral formation in the spinal cord}

At later phases of CS axon collateral formation in the spinal cord, we observed significantly more axon collaterals in the dorsal ( $p=$ $0.006)$, medial $(p=0.0086)$, and ventral $(p=0.0036)$ spinal cord regions of P10 Npn-1 ${ }^{f l f f}$; Emxl-Cre $(n=6)$ mice compared with control mice ( $n=7$; Fig. 4 ).

To visualize a unilateral subset of CSNs and their descending CS axons, we injected AAV1-CAG-tdTomato $\left(1 \times 10^{11} \mathrm{GC} / \mathrm{ml}\right.$, $200 \mathrm{nl} /$ injection) into one hemisphere of the sensorimotor cortex of Npn-1 ${ }^{f l /+} ; \operatorname{Emx1-Cre}(n=6)$ and Npn-1 $1^{f l f l} ; \operatorname{Emxl-Cre}(n=7)$ mice at $\mathrm{P} 4$. The overall morphologies and trajectories of CS tracts within the brains of 6-week-old Npn-1 $1^{f l f l}$; Emx1-Cre mice were comparable to those of control mice (Fig. 5A-H). We also found that similar numbers of CS axons in the dorsal funiculus of the lumbar spinal cord were labeled by AAV1-CAG-tdTomato in both groups $(p=0.6426$; Fig. $5 M, U, Y)$. In contrast, we observed a significant increase in CS axon collaterals in the dorsal $(p=0.0091)$, medial $(p<0.0001)$, and ventral $(p=0.0001)$ regions of the lumbar spinal cord in Npn-1 $1^{f l f l}$; Emx1-Cre mice (Fig. 5R-T) compared with $N p n-1^{f l /+}$; Emx1-Cre (Fig. 5J-L) mice. CS boutons associated with these exuberant axon collaterals in $N p n-1^{f l f f}$; Emx1-Cre mice were found to be positive for the presynaptic marker vGlut ${ }^{+}$(Fig. $5 \mathrm{~V}-$ $X)$. In summary, depleting $N p n-1$ in CSNs results in a marked increase of axon collaterals within the spinal cord.

We then investigated whether Npn-1 $1^{f l f l}$; Emx1-Cre mice have defects in cortical projections to other areas of the brain such as the red nucleus and brainstem. We injected $A A V$-TdTomato into one hemisphere of the sensorimotor cortex of P7 Npn-1 ${ }^{f l++}$; Emx1-Cre and Npn-1 $1^{f l f l}$; Emxl-Cre mice and analyzed the mice $7 \mathrm{~d}$ later (P14). We found no obvious differences in cortical projections to the red nucleus (Fig. $6 A, B$ ) or the brainstem (Fig.

$\leftarrow$

(Figure legend continued.) shafts in both groups. Q, S, High-power views of the red boxed areas in $\boldsymbol{P}$ and $\boldsymbol{R}$. The primary axon shafts are divided into three groups based on the orientation of their projections (I, dorsal; II, medial; III, ventral). $I$, Quantification of the axon collaterals in zones I $(p=0.1950)$, II $(p=0.6826)$, and III $(p=0.8295)$ showed that the numbers of axon

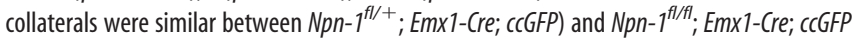
mice. Scale bars: $\boldsymbol{B}, 1 \mathrm{~mm} ; \boldsymbol{N}, 50 \mu \mathrm{m} ; \boldsymbol{R}, 200 \mu \mathrm{m} ; \boldsymbol{S}, 150 \mu \mathrm{m}$. n.s. $=$ not significant.
$6 \mathrm{C}-\mathrm{F}$ ) between $\mathrm{Npn-1}{ }^{f l /+} ; \mathrm{Em} \times 1-\mathrm{Cre}$ and Npn-1${ }^{f l / f l}$; Emx1-Cre mice. Moreover, we did not find any obvious defects in axonal decussation of CSNs in the brainstem in Npn-1 ${ }^{f l / f l}$; Emx1-Cre mice compared with $N p n-1^{f l /+}$; Emxl-Cre mice (Fig. 6C-F). Therefore, defects in CS axonal projections seem to be restricted to the spinal cord but not the brain in Npn-1 ${ }^{f l / f l}$; Emx1-Cre mice.

\section{Exuberant CS axons in the spinal cord of Sema3A $A^{-/-}$mice}

To examine the effects of Sema3A deletion on the formation of CS axon collaterals in the spinal cord in vivo, we analyzed the arborization of $\mathrm{GFP}^{+} \mathrm{CS}$ axons in the lumbar spinal cord of control $\left(\right.$ Sema3A $A^{+/-}$; Emx1-Cre; ccGFP, $\left.n=6\right)$ and Sema3A mutant $\left(\right.$ Sema3 $A^{-/-}$; Emx1-Cre; ccGFP, $n=6$ ) mice at P10 (Taniguchi et al., 1997). We found that the majority of CS axon collaterals in P10 control mice were confined to the dorsal spinal cord (Fig. $7 A, D, F, H)$, whereas the axon collaterals in Sema3 $A^{-1-}$ mice were found in the dorsal, medial, and ventral regions. In the dorsal spinal cord, there was no difference $(p=0.2154)$ in axon collaterals between control and Sema3 $A^{-/-}$mice (Fig. $7 A-E$ ). However, observed significant increases in axon collaterals in the medial $(p=0.0114, t$ test $)$ and ventral ( $p=0.0194)$ regions of the lumbar spinal cord in Sema3 $A^{-/-}$mice compared with controls (Fig. $7 A-C, F-I$ ).

To examine the morphologies and trajectories of axon collaterals in the adult spinal cord, we injected AAV1-CAG-tdTomato $\left(1 \times 10^{11} \mathrm{GC} / \mathrm{ml}, 200 \mathrm{nl} /\right.$ injection) into left hemisphere of the sensorimotor cortex at P4 to unilaterally label a subset of CSNs. The overall morphologies and trajectories of the labeled CS tracts within the brains of 6-week-old Sema3 $A^{-/-}$mice were comparable to those observed in Sema3 $A^{+/-}$mice (Fig. $8 A-H$ ). We also found that similar numbers of axons in the dorsal funiculus of the lumbar spinal cord were labeled by $A A V 1-C A G$-tdTomato in Sema3 $A^{+/-}(n=6)$ and Sema3 $A^{-/-}$mice $(n=6 ; p=0.1668$; Fig. $8 M, U, Y)$. In contrast, we found a significant increase in axon collaterals in the medial $(p=0.0004)$ and ventral $(p<0.0001)$, but not dorsal $(p=0.9141)$, regions of the lumbar spinal cord in Sema3 $A^{-1-}$ mice (Fig. $8 R-T$ ) compared with those of Sema3 $A^{+/-}$mice (Fig. 8J-L). CS boutons associated with these exuberant axon collaterals in the ventral lumbar spinal cord of Sema3 $A^{-/-}$mice were found to be vGlut ${ }^{+}$(Fig. $8 U-X$ ). Together, these results suggest that secreted Sema3A is required for inhibiting CS axon collateral formation in the spinal cord.

\section{Npn-1 and Sema3A deletion disrupt topographic innervation of sensory CST}

We recently reported that the CSTs from the sensory and motor cortices project axons into the dorsal and ventral spinal cord in mice, respectively (Ueno et al., 2018). Building upon this finding, we examined whether Sema3A-Npn-1 signaling is involved in sensory CST innervation in the dorsal spinal cord. To test whether Sema3A expressed in the ventral cervical gray matter (Fig. $1 C, D, G, H$ ) acts as a repellent molecule to influence sensory CS axon innervation in the dorsal spinal cord, we labeled the sensory CSTs of $N p n-1^{f l / f l}$; EmxlCre $(n=3)$ and Sema3 $A^{-/-}(n=3)$ mice by injecting a small volume of an anterograde tracer, BDA, into the sensory cortex. In control mice $(n=3)$, sensory CS axons innervated mainly the dorsal regions of the spinal gray matter and were mostly absent from the ventral region (Fig. 9A; lamina VII-X), as previously reported (Ueno et al., 2018). In contrast, marked ventral innervation of sensory CS axons was observed over the medial-ventral border of the gray matter in Sema3a and Npn-1 mutant mice $(p=0.0024,0.0492$; Fig. $9 A-D)$. Together, these results indicate that Sema3A-Npn-1 signals contribute to the precise topographic distribution of CS axons from the sensory cortex. 


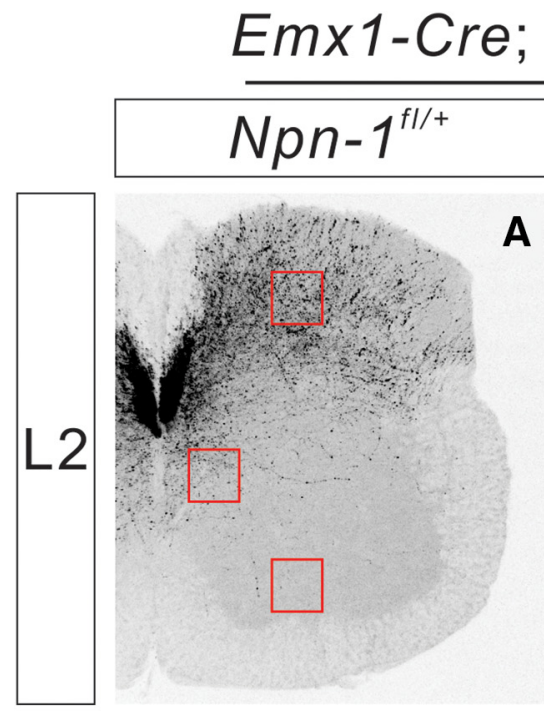

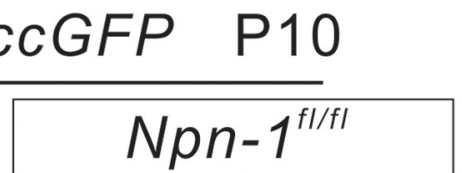

A

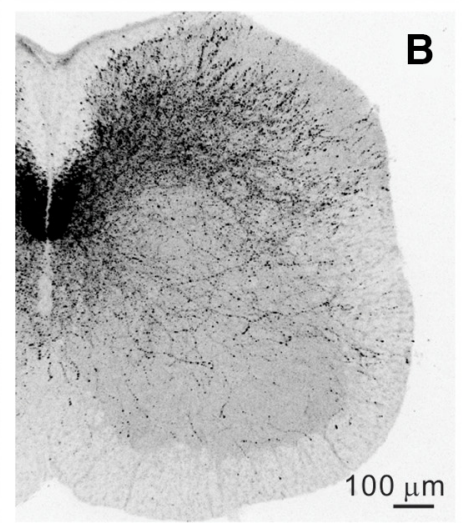

C

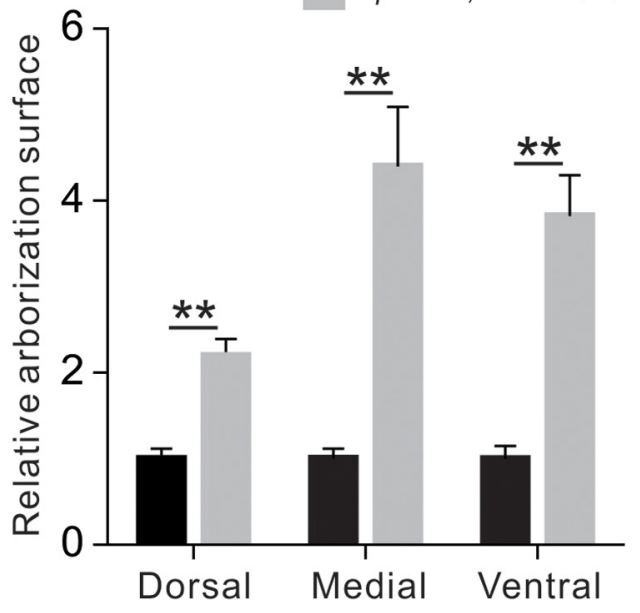

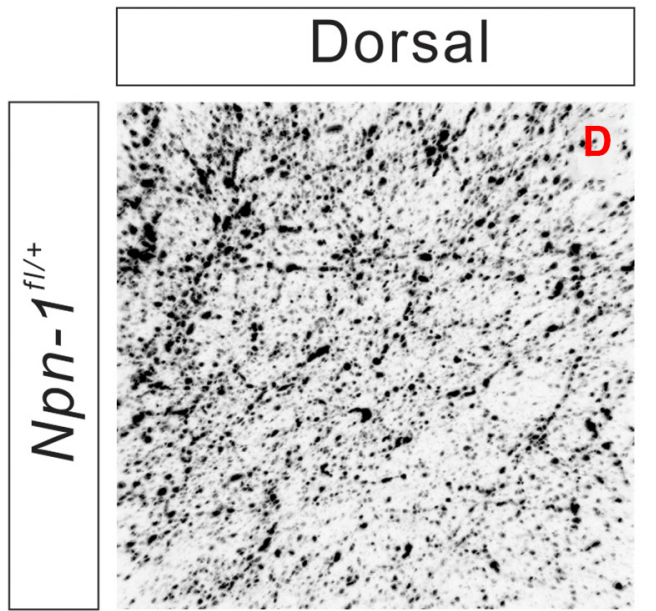
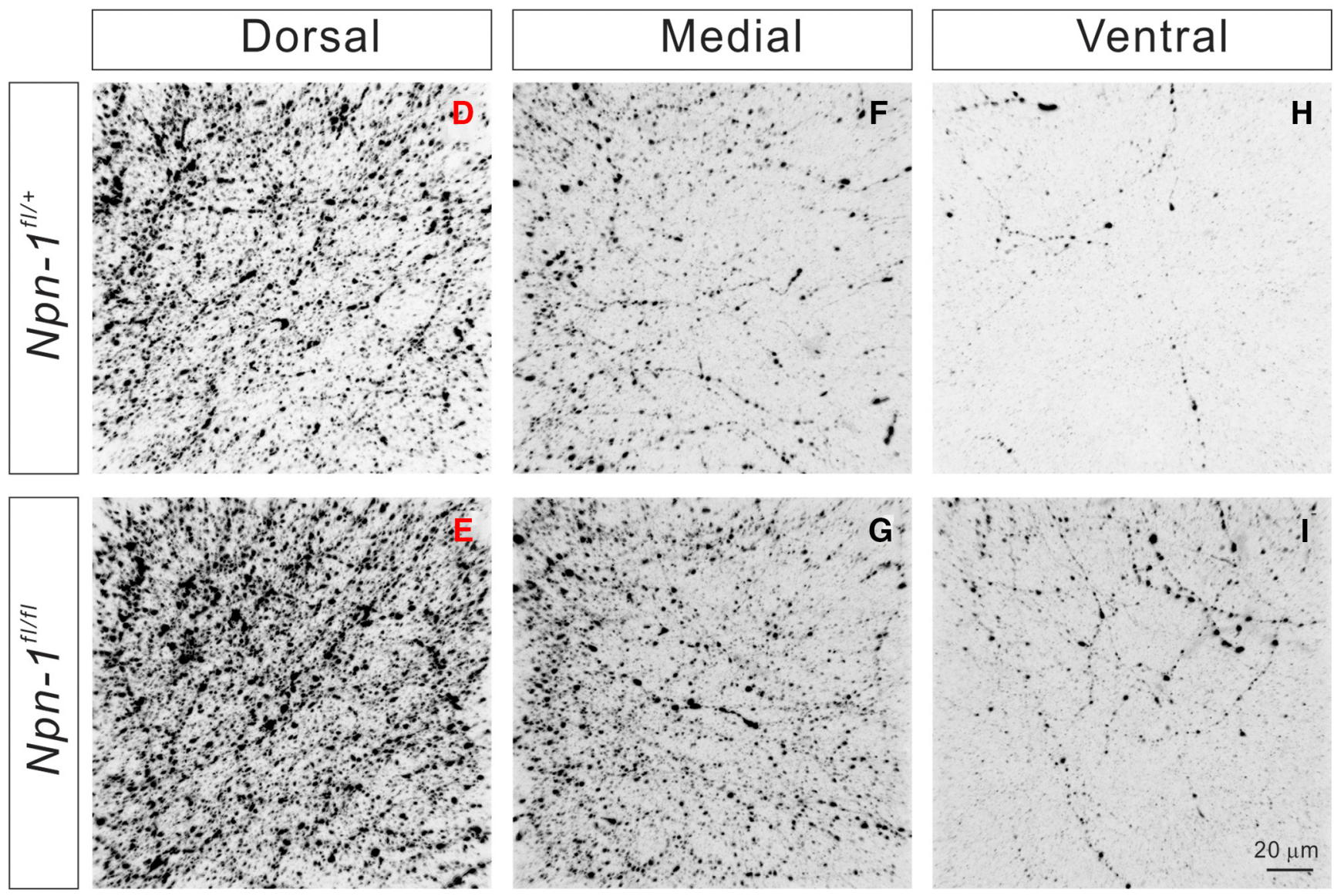

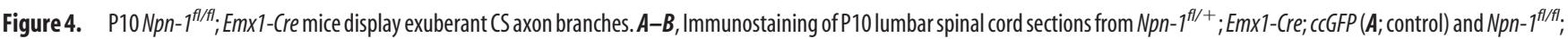
Emx1-Cre; cCGFP mice (B) using antibodies targeting GFP. Regions with a high-power view are indicated by red squares. C, Quantification of axon collateral intensity shows Npn-1/f/fl; Emx 1 -Cre; $C c G F P$ mice had significantly more axon collaterals in the dorsal $(p=0.006)$, medial $(p=0.0086)$, and ventral $(p=0.0036)$ regions of the lumbar spinal cord compared with controls. $\boldsymbol{D}$-I, High-power

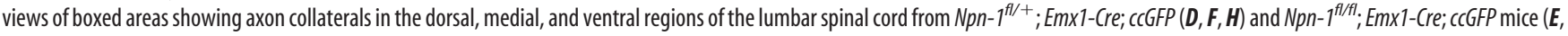
G, I). Scale bars: $\boldsymbol{B}, 100 \mu \mathrm{m} ; \boldsymbol{I}, 20 \mu \mathrm{m} .{ }^{* *} P<0.01$.

Adult Npn-1 ${ }^{f l f f} ;$ Emx1-Cre mice exhibit deficits in skilled movements

When we studied the impact of CS axon collateral defects in the spinal cord on motor behaviors, we did not find any changes in forelimb $(p=0.6970, t$ test $)$ or hindlimb $(p=0.7098)$ grip strength in Npn-1 $1^{f l f f} ;$ Emxl-Cre mice $(n=8)$ compared with those of control (Npn-1 flffl, $n=8)$ mice (Fig. 10A).

The same mice were then challenged with different skilled behavioral tests. First, we assessed forelimb behaviors using a single-pellet reaching task in which mice were trained to reach 

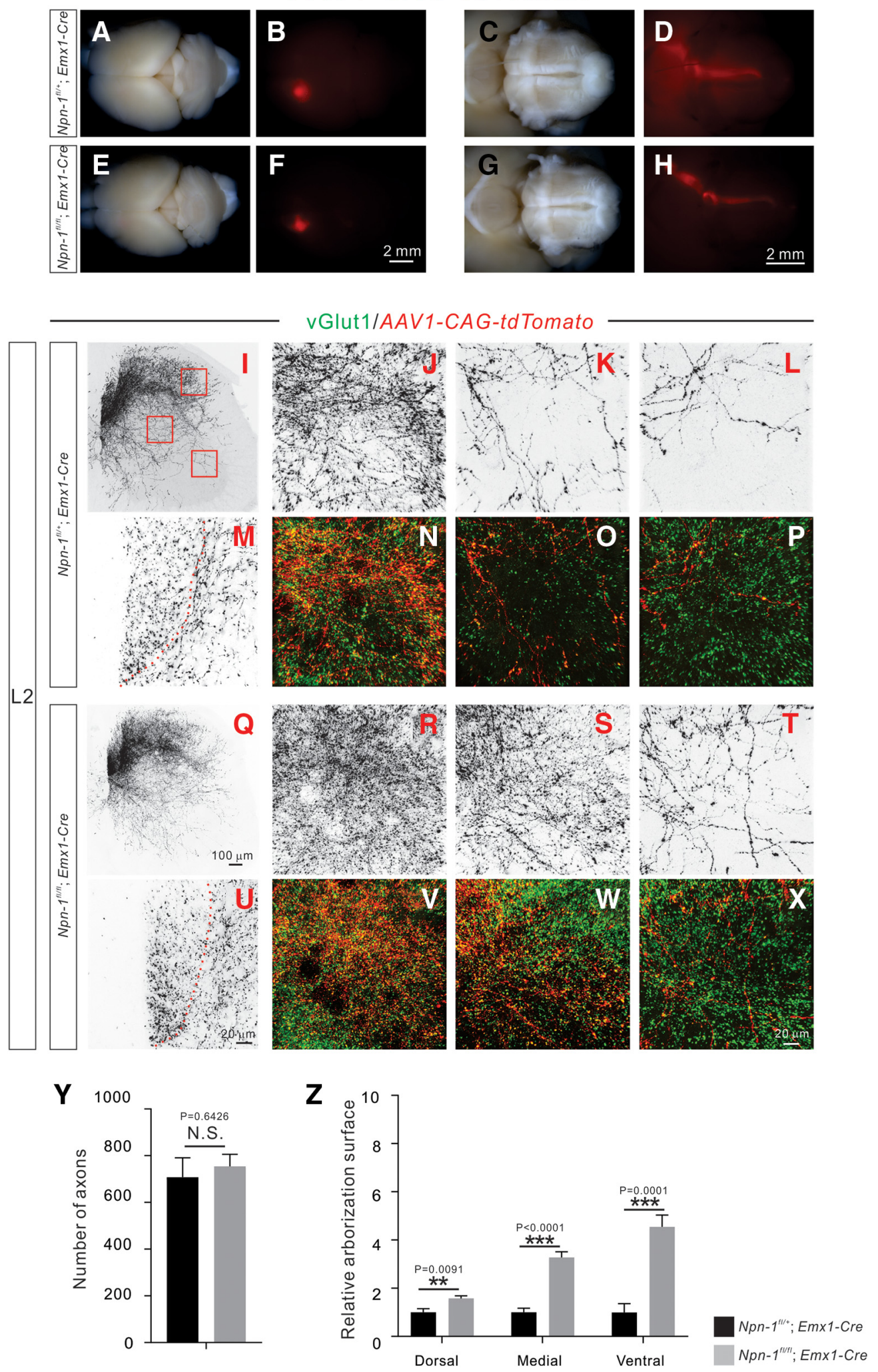

Figure 5. Adult Npn- $1^{f / f f} ;$ Emx1-Cre mice display exuberant $C S$ axon branches. $\boldsymbol{A}-\boldsymbol{H}$, Anterograde tracing strategy to label unilateral CSNs and their descending axons. Top views of the brain show the cortical neurons that were labeled by AAV1-CAG-tdTomato in 6 week-old Npn- $7^{f / /+} ; E m \times 1-C r e(A, B ; n=6)$ and Npn-1/f/fl; Emx1-Cre $(\boldsymbol{E}, \boldsymbol{F} ; n=7)$ mice. Ventral views of the brainstem show CS

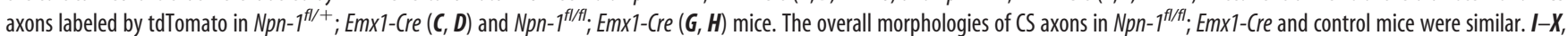
Immunofluorescent labeling of lumbar spinal cord sections using antibodies targeting tdTomato (red; shown in black except in $\boldsymbol{N}-\boldsymbol{P}, \boldsymbol{V}-\boldsymbol{X}$ ) and vGlut1 (green). Transverse views show the $\mathbf{C S}$

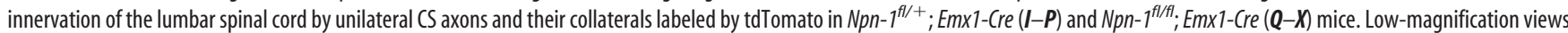
$(\boldsymbol{I}, \mathbf{Q})$ show $C$ innervation of the lumbar spinal cord. High-magnification views $(\boldsymbol{M}, \boldsymbol{U})$ of the dorsal funiculus show individual CS axons labeled by $\operatorname{tdT}$ Tomato. The dorsal $(\boldsymbol{J}, \boldsymbol{N}, \boldsymbol{R}, \boldsymbol{V}$, medial $(\boldsymbol{K}, \boldsymbol{O}, \boldsymbol{S}$, $W$ ), and ventral $(L, P, T, X)$ spinal cord (high-magnification views from Fig. 5l,Q), showing exuberant CS axon branches in Npn- $1^{f t / f l} ;$ Emx 1 -Cre mice. CS boutons labeled by tdTomato were colocalized with the presynaptic marker vGlut1. $Y$, Quantification of tdTomato-labeled CS axons showing similar ( $p=0.6426)$ numbers between mutant and control mice. (Figure legend continues.) 


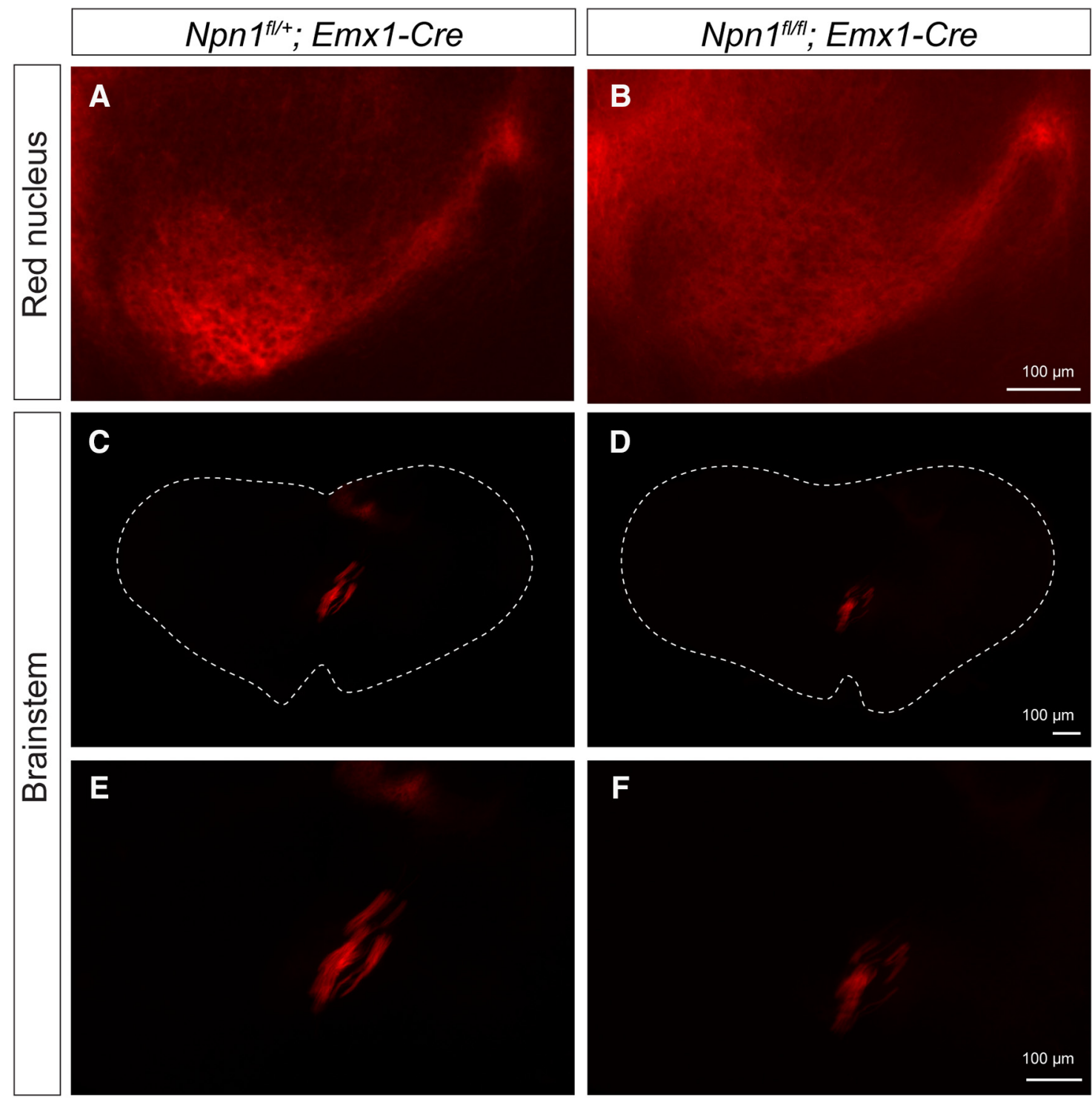

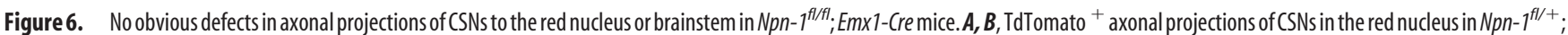

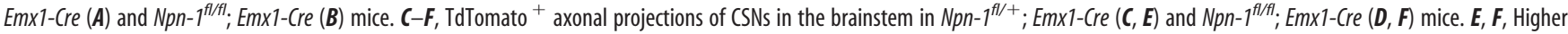
magnifications of $\boldsymbol{C}$ and $\boldsymbol{D}$, respectively. Scale bars, $100 \mu \mathrm{m}$.

through a slit inside a test chamber to grasp a food reward (Fig. $10 B$; Xu et al., 2009) Control mice improved their performance over time, reaching a peak success rate of $\sim 45 \%$ by Day 7 (Fig. 10C). In contrast, we observed a consistently lower rate of success throughout the testing period with Npn-1 ${ }^{f l f l} ; E m \times 1$ Cre mice ( $n=8$; Fig. $10 C$ ). Their performance was compromised from the outset, and by Day 7 they had only achieved a success rate of $\sim 13 \%$ (Fig. 10C). Overall, the performance of $N p n-1^{f l f l}$; Emx1-Cre mice was significantly lower than control mice $(p<0.0001$, two-way ANOVA, followed by post hoc comparisons) in this skilled forelimb behavioral task.

To test motor coordination, we placed mice on an accelerating rotarod (Daily et al., 2011) and measured the length of

(Figure legend continued.) $\quad$ Z, Quantification of axon collateral intensities showing that Npn$7^{f l / f f} ;$ Emx1-Cre mice had significantly more axon collaterals in the dorsal ( $\left.p=0.0091\right)$, medial $(p<0.0001)$, and ventral $(p=0.0001)$ regions of the lumbar spinal cord compared with Npn- $7^{f /+}$;Emx1-Cre mice. Scale bars: $\boldsymbol{F}, \boldsymbol{H}, 2 \mathrm{~mm} ; \mathbf{Q}, 100 \mu \mathrm{m} ; \boldsymbol{U}, \boldsymbol{X}, 20 \mu \mathrm{m}$. time they could stay on the rotating cylinder (latency to fall). The performance on this test of both control and $N p n-1^{f l / f l}$; Emx1-Cre mice improved progressively over the course of 8 trials (Fig. 10D). However, the latency to fall per trial for $N p n-1^{f l / f l}$; Emx1-Cre mice was significantly lower than that of control mice $(p<0.0001$, two-way ANOVA, followed by post hoc comparisons; Fig. 10D).

We then subjected mice to a grid-walking test to evaluate their ability to accurately grasp rungs with their forepaws during spontaneous exploration of an elevated grid (Z'Graggen et al., 1998; Starkey et al., 2005). Npn-1 ${ }^{f l / f l}$; Emxl-Cre mice exhibited more frequent forelimb foot-slips than control mice $(p=0.0016)$ during this task (Fig. 10E,F).

Finally, fine motor coordination and balance in the hindlimbs were assessed in a beam walking test (Fig. 10G), which involved mice walking across elevated narrow beams of varying widths (4, 8 , and $16 \mathrm{~mm}$ ) to a safe platform. Performance on this task was measured by recording both the time required to traverse the beam and the number of hindlimb paw slips observed (Luong et 

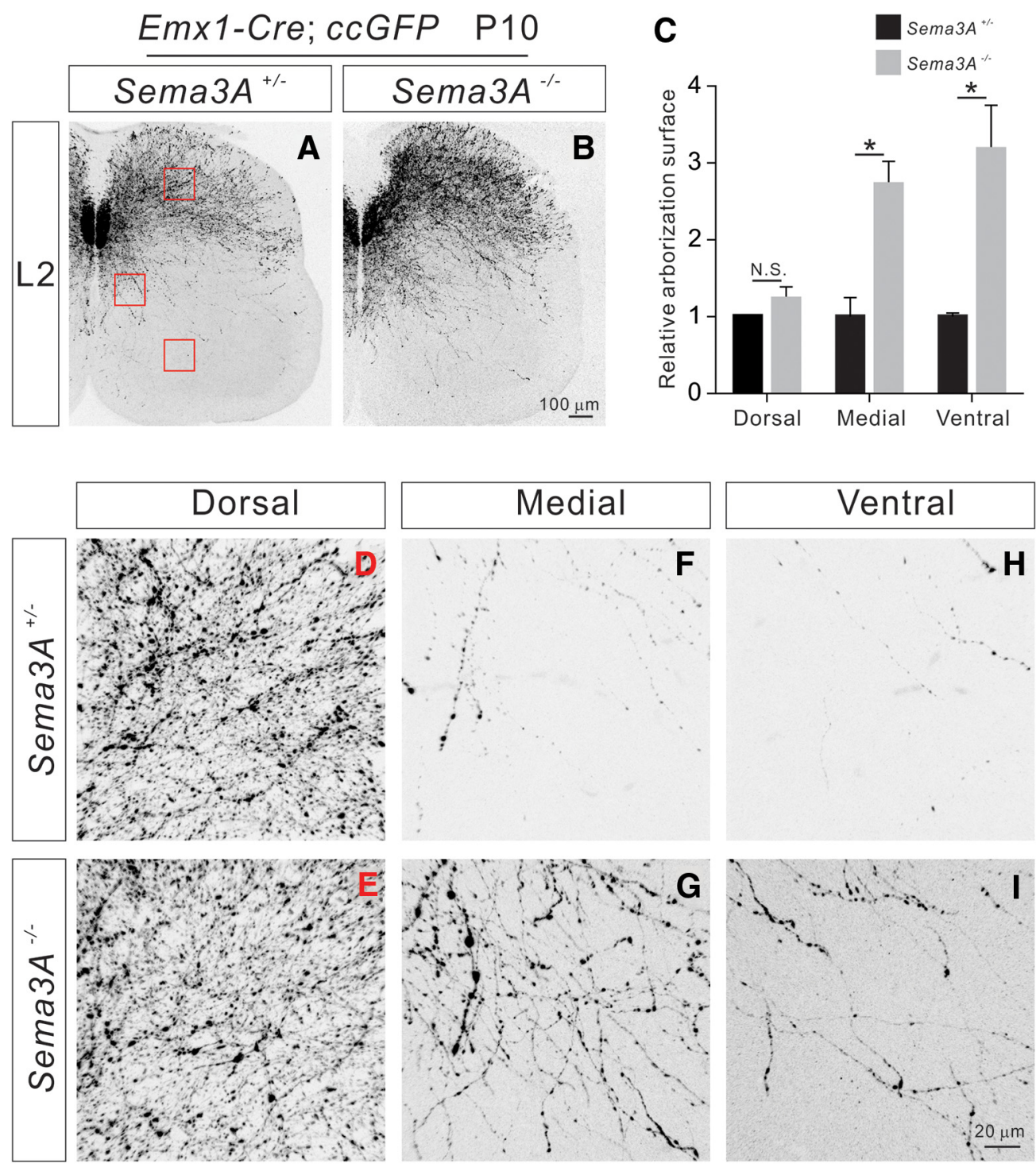

Figure 7. P10 Sema3 $A^{-1-}$ mice display exuberant CS axon collateral formation. $\boldsymbol{A}, \boldsymbol{B}$, Immunostaining of P10 lumbar spinal cord sections from Emx1-Cre; $c \mathrm{CGFP}\left(\boldsymbol{A} ;\right.$; control) and Sema3 $A^{-1-}$; Emx1-Cre; cCGFP mice (B) using antibodies targeting GFP. Regions with high-power views are indicated by red squares. $\boldsymbol{C}$, Quantification of axon collateral intensities, showing Sema3A ${ }^{-/-}$; Emx1-Cre; cCGFP mice had significantly more axon collaterals in the medial $(p=0.0114)$ and ventral $(p=0.0194)$ but not dorsal $(p=0.2154)$ regions of the lumbar spinal cord compared with

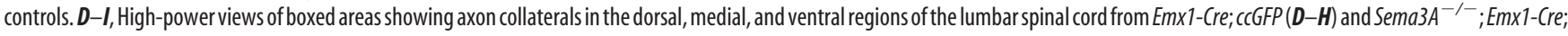
CCGFP mice $(\boldsymbol{E}-\boldsymbol{I})$. Scale bars: $\boldsymbol{B}, 100 \mu \mathrm{m} ; \boldsymbol{I}, 20 \mu \mathrm{m} .{ }^{*} P<0.05$, n.s. $=$ not significant.

al., 2011). In this test, $N p n-1^{f l f l}$; Emx1-Cre mice exhibited more frequent hindlimb foot-slips compared with control mice on every beam width $(4 \mathrm{~mm}, p=0.0021 ; 8 \mathrm{~mm}, p=0.0181 ; 16 \mathrm{~mm}$, $p=0.0162$; Fig. 10H). Together, these results demonstrate that skilled movements are compromised in Npn-1 flffl Emxl-Cre mice. These findings also suggest that Sem3A-Npn-1 signalingmediated inhibition of CS axon collateral formation is critical for the proper formation and function of the CS circuits that underlie skilled movements.

\section{Discussion}

Mammalian CS circuits are the principal circuits of voluntary motor control. The formation of functional CS circuits is contingent upon the completion of numerous highly orchestrated events, such as the fasciculation, guidance, and branching of growing CS axons. In this work, we examined the role of Sema3A-Npn-1 signaling in the development of CS circuits. Our results strongly suggest that the interactions between Sema3A and Npn-1 suppress the collateral formation of CS axons within the spinal gray matter. Disruption of this pathway results in exuberant CSN axon collaterals in the spinal cord. Skilled behaviors are compromised in Npn-1-deficient mice, indicating that exuberant CS axons in the ventral spinal cord of $N p n-1$ mutant mice do not form appropriate connections and may even disrupt other intact CS circuits, such as those in the dorsal spinal cord. Together, our genetic findings indicate that Sema3A-Npn-1 signaling-mediated inhibition of CS axon collateral formation is critical for the establishment of the CS circuits underlying skilled movements.

\section{Sema3A-Npn-1 signaling suppresses axon collateral formation in CSNs in the spinal cord}

CS axons descend from the sensorimotor cortex through the brainstem and extend to the spinal cord where they branch and find their appropriate target neurons. CS axons innervate their spinal targets by extending collateral branches interstitially along 

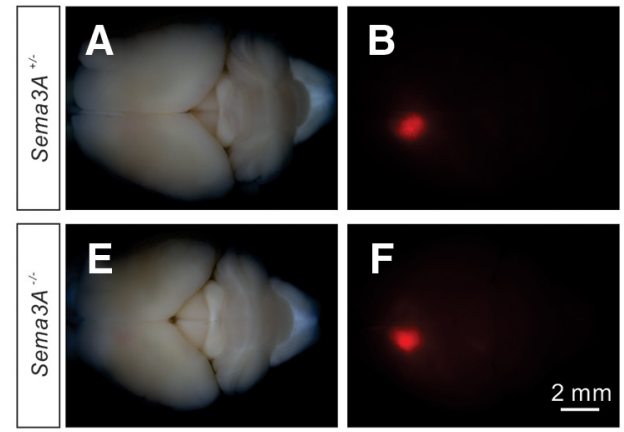
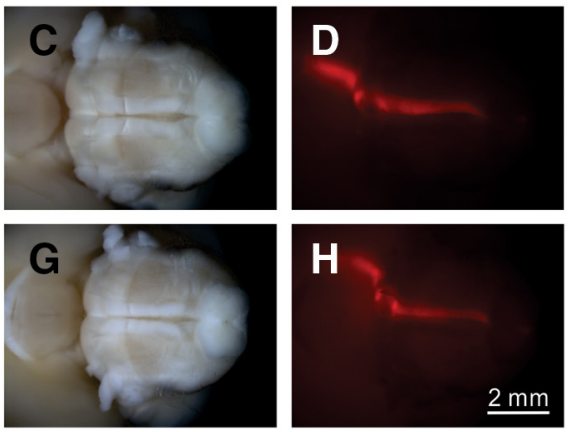

\section{vGlut1/AAV1-CAG-tdTomato}
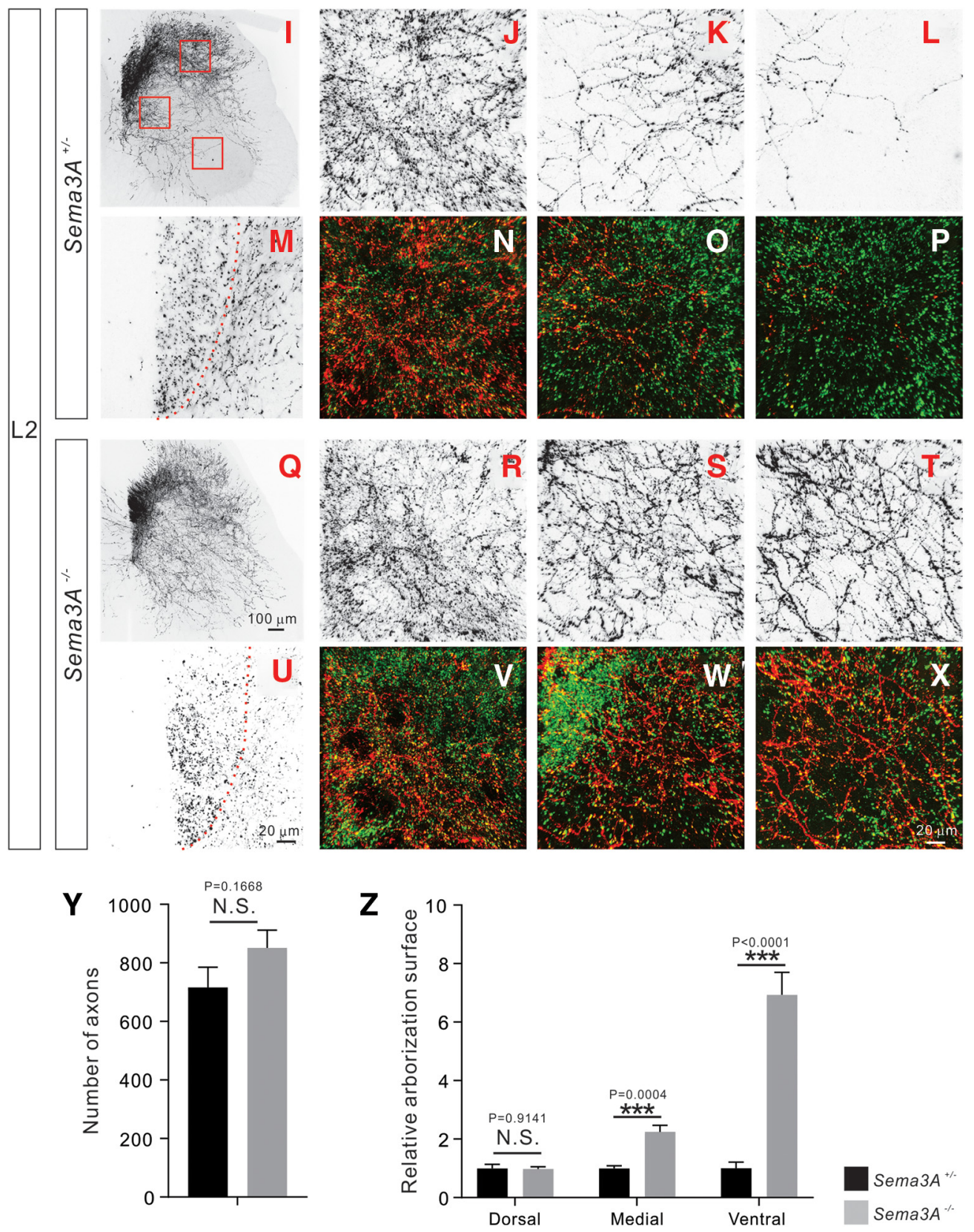

Figure 8. Adult Sema $3 A^{-/-}$mice display exuberant CS axon branches. $\boldsymbol{A}-\boldsymbol{H}$, Anterograde tracing strategy to label subsets of CSNs and their descending axons. Top views of the brain, showing

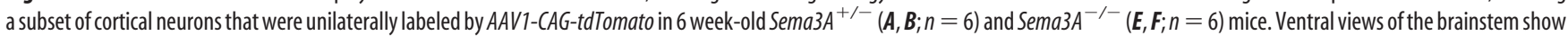
CS axons labeled by tdTomato in Sema3 $A^{+/-}(\boldsymbol{C}, \boldsymbol{D})$ and Sema3 $A^{-/-}(\mathbf{G}, \boldsymbol{H})$ mice. The overall morphologies of $\left(\mathrm{S}\right.$ axons in Sema $3 A^{-/-}$mice were similar to what was observed in control mice. I-X, Immunofluorescent labeling of lumbar spinal cord sections using antibodies targeting tdTomato (red; shown in black except in $\boldsymbol{N}-\boldsymbol{P}, \boldsymbol{V}-\boldsymbol{X}$ ) and vGlut 1 (green). Transverse (Figure legend continues.) 

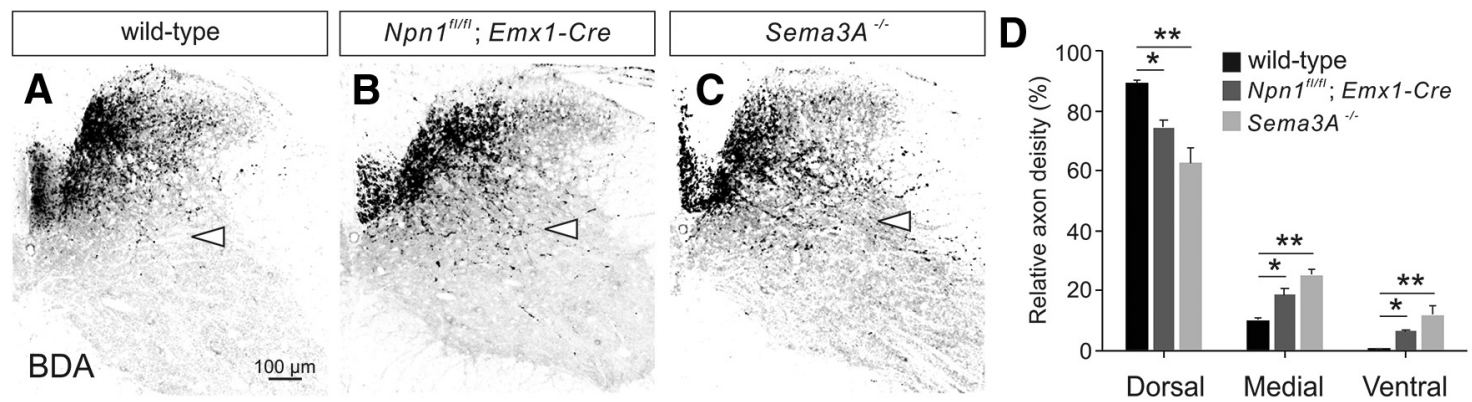

Figure 9. Npn-1 and Sema3A are required for topograhic innervation of sensory $C S$ axons into the dorsal spinal cord. $A-C$, BDA-labeled sensory CST fibers in transverse cervical cord sections of

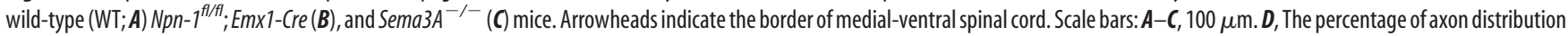
of sensory CST in the dorsal, medial, and ventral spinal gray matter. ${ }^{*} p<0.05,{ }^{* *} p<0.01$ (one-way ANOVA followed by Tukey's test).

their length (Bastmeyer and O'Leary, 1996). This process involves the de novo formation of axon branches from the axon shaft independent of the growth cone present at the distal-most segment of the axon (Gallo, 2011). However, little is known about the molecular regulation of CS axon collateral formation (Canty and Murphy, 2008). Here, we show that Sema3A-Npn-1 signaling, although being unnecessary for earlier phases of CS circuit formation, plays an important role specifically in axon collateral formation. For example, initial guidance of CS axons in the spinal cord, CS axon trajectories in the brain, and the dorsal tuning and midline crossing of CS axons in the brainstem were indistinguishable from controls in Sema3A and Npn-1 mutant mice. When it came to axon collateral formation in the spinal cord, we found defects in both Sema3A and Npn-1 mutant mice. The defects were slightly different in CS axon collateral formation in Sema3A and Npn-1 mutants suggesting that other ligands or receptors may also bind to Sema3A or Npn-1 to regulate CS axons although we cannot simply compare defects using null and conditional mutant animals.

An important question remains about whether Sema3ANpn-1 signaling inhibits the branching or the length of CS axon collaterals or both. Distinguishing between additional CS axonal branching and increased CS axon length in Npn-1 mutant mice would be very difficult, thus, we cannot make any conclusions on these finer points of Sema3A-Npn-1 signaling at this time. It is possible that the particular role of Sema3A-Npn-1 signaling might depend upon the concentration of Sema3A in vivo. For example, a high concentration of Sema3A may inhibit the length of CS axon branching, whereas a low concentration may inhibit only the numbers of CS axon branches. Nevertheless, our results strongly suggest that Sema3A-Npn-1 signaling is required for proper CS axon collateral formation in the ventral spinal cord.

Because Npn-1 does not have an intracellular domain, its coreceptors, which are members of the Plexin A (PlexA) family, transduce the Sema3A signal (Tran et al., 2007). Previous studies

\footnotetext{
$\leftarrow$

(Figure legend continued.) views show CS innervation of the lumbar spinal cord by the unilateral CS axons and their collaterals labeled by tdTomato in Sema3A $A^{+-}(\boldsymbol{I}-\boldsymbol{P})$ and Sema3 $A^{-1-}(\mathbf{Q}-\boldsymbol{X})$ mice. Low-magnification views $(\boldsymbol{I}, \mathbf{Q})$ show $C$ innervation of the lumbar spinal cord. High-magnification views $(\boldsymbol{M}, \boldsymbol{U})$ of the dorsal funiculus show individual $C S$ axons labeled by tdTomato. High-magnification views of the dorsal $(\boldsymbol{J}, \boldsymbol{N}, \boldsymbol{R}, \boldsymbol{V})$, medial $(\boldsymbol{K}, \mathbf{O}, \boldsymbol{S}, \boldsymbol{W})$, and ventral $(\boldsymbol{L}, \boldsymbol{P}, \boldsymbol{T}, \boldsymbol{X})$ spinal cord show exuberant $\mathrm{CS}$ axon branches in Sema3 $A^{-/-}$mice. CS boutons labeled by tdTomato were colocalized with the presynaptic marker vGlut1. $Y$, Quantification showing the labeling of a similar ( $p=0.1668$ ) number of CS axons by tdTomato. $Z$, Analysis of axon collateral intensity showing Sema $3 A^{-/-}$mice had significantly more axon collaterals in the medial $(p=0.0004)$, and ventral $(p<0.0001)$ regions of lumbar spinal cord compared with Sema3 $A^{+/-}$mice. Scale bars: $\boldsymbol{F}, \boldsymbol{H}, 2 \mathrm{~mm} ; \boldsymbol{Q}, 100 \mu \mathrm{m} ; \boldsymbol{U}, \boldsymbol{X}, 20 \mu \mathrm{m}$.
}

using loss-of-function experiments suggested that PlexA3 and PlexA4 transduce the Sema3A-mediated signal (Cheng et al., 2001; Yaron et al., 2005), whereas PlexA1 and PlexA2 relay class 6 semaphorin signals (Yoshida et al., 2006; Suto et al., 2007; Ebert et al., 2014; Sun et al., 2015). Although PlexA1 mutant mice show increased CS axonal projections/branches in the ventral spinal cord, this phenotype is likely because of defects in CS axon pruning initiated by the Sema6D ligand (Gu et al., 2017a). Future studies will examine CS axonal projections/branches in the spinal cord of PlexA3/A4 double mutants as well as PlexA2 mutant mice to genetically determine which coreceptors of Npn-1 regulate CS axonal branches in the ventral spinal cord.

\section{Roles of semaphorins and L1CAM in decussation of CS neurons}

Previous studies reveal that L1CAM modulates Sema3A signaling in cortical neurons (Castellani et al., 2000, 2002, 2004; Bechara et al., 2008; Law et al., 2008; Dang et al., 2012). L1CAM binds to Npn-1 receptors (Castellani et al., 2000), whereas Sema3A repels axons of cortical neurons using cortical slices from wild-type, but not L1CAM mutant mice (Castellani et al., 2000, 2002). Moreover, L1CAM mutant mice show defects in axon decussation of CSNs in the brainstem (Cohen et al., 1998; Jakeman et al., 2006). In our study, Npn-1 mutant mice did not show any obvious CS axon decussation defects in the brainstem (Fig. 6), although we still cannot exclude the possibility that Npn-1 has some roles in controlling CS axon decussation. These findings may suggest that L1CAM modulates not only Sema3A but also other semaphorin signaling pathways in vivo. Because class 6 semaphorins control CS axon decussation in the brainstem (Faulkner et al., 2008; Rünker et al., 2008), future studies will explore the effects of L1CAM on class 6 semaphorins.

\section{Proper formation of CS axon collaterals is critical for skilled movements}

We previously showed that PlexA1 mutant mice with direct connections between CSNs and motor neurons exhibited elevated skilled motor behaviors (Gu et al., 2017a). Therefore, we hypothesized that if excess CS collateral formations in the ventral spinal cords of Npn-1 mutant mice form proper connections with spinal interneurons or ectopic direct connections with motor neurons, Npn-1 mutant mice may display normal or even enhanced skilled movements. However, in our behavioral assays, $N p n-1$ mutant mice actually performed worse in tests involving skilled motor control (Fig. 10). This suggests that CS axons in the ventral spinal cord of Npn-1 mutant mice fail to form monosynaptic connections with motor neurons or proper connections with appropri- 
A

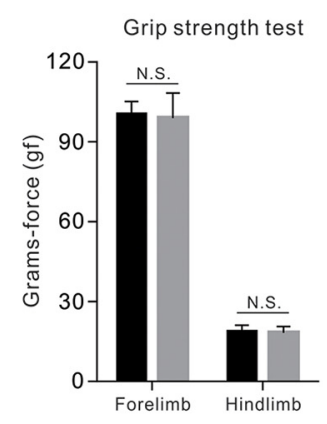

B

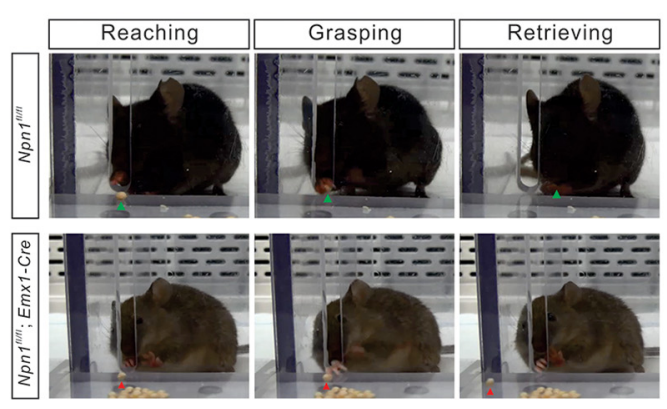

C

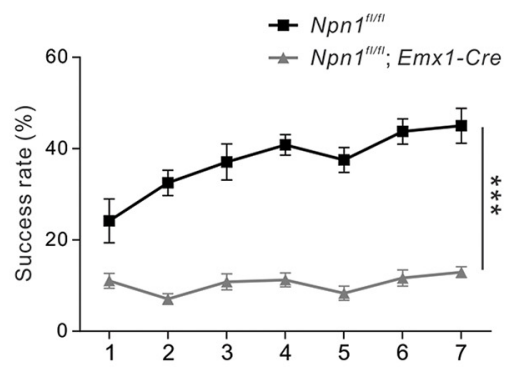

D

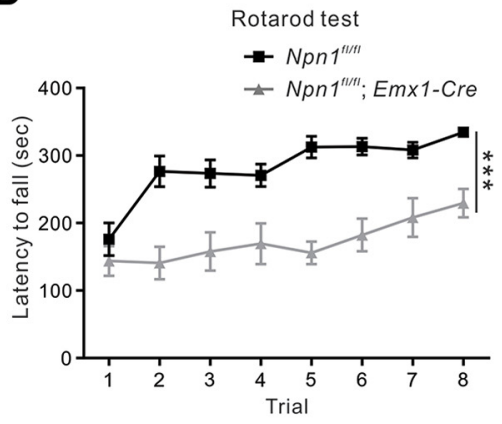

G

Beam walking test
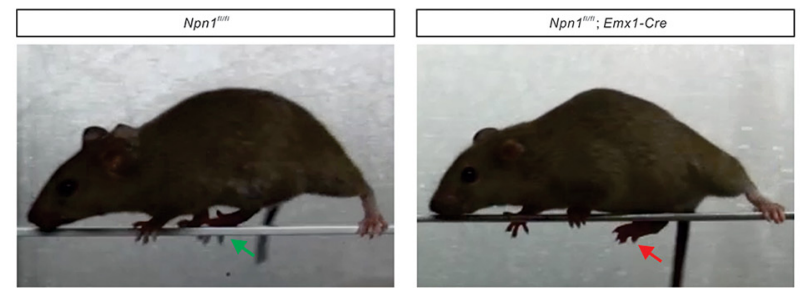

E

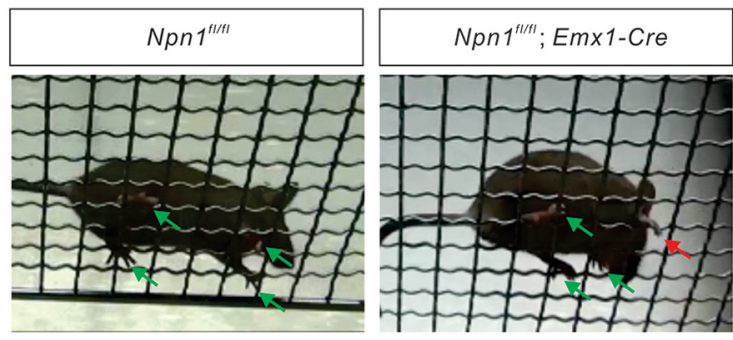

F

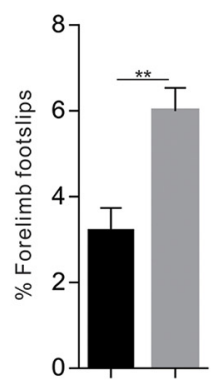

H

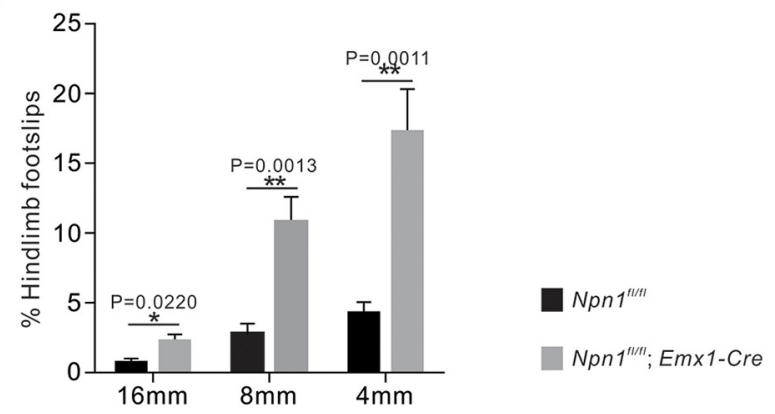

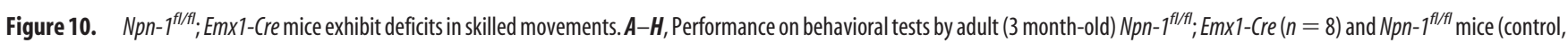
$n=8)$. $\boldsymbol{A}$, The grip-strength test showed that forelimb $(p=0.6970)$ and hindlimb $(p=0.7098)$ strength was not altered in Npn- $7^{f / f l} ;$ Emx 1 -Cre mice. $\boldsymbol{B}$, Video snapshots of the reaching test showing the reaching, grasping, and retrieving phases. The firm grip of the pellet with finger control during the grasping phase led to successful retrieval, whereas the Npn- ${ }^{f / f f l}$; Emx 1 -Cre mouse did not exhibit a proper grip. $C$, Quantification of the number of successful attempts showing that the success rate in the reaching test for Npn- $f^{f / f f}$; Emx 1 -Cre mice was significantly lower than that of control mice $(p<0.0001)$. D, Comparison of latencies to falling in the rotarod test showed that Npn-7f/ff; Emx1-Cre mice outperformed control mice in the time they could remain on the rotating $\operatorname{rod}(p<0.0001)$. $\boldsymbol{E}$, Video snapshots of the grid-walking test. The successful placements of paws are denoted by green arrows, while a forelimb foot-slip is indicated by the red arrow. $\boldsymbol{F}$, Comparison of forelimb foot-slips during the grid-walking test showed that the percentage of foot-slips for Npn- $7^{f / f f} ;$ Emx 1-Cre mice was significantly higher than that of control mice ( $\left.p=0.0016\right)$. G, Video snapshots of control and Npn-1/f/fl; Emx1-Cre mice on an $8 \mathrm{~mm}$ beam. $\boldsymbol{H}$, Comparison of hindlimb foot-slips during the beam-walking test showing that the Npn- $1^{f / / f l} ;$ Emx 1 -Cre mice experienced significantly more foot-slips than control mice $(16 \mathrm{~mm}, p=0.0220 ; 8 \mathrm{~mm}, p=0.0013 ; 4 \mathrm{~mm}, p=0.0011)$. ${ }^{* *} p<0.01,{ }^{* * *} p<0.001$, n.s. $=$ not significant.

ate spinal interneurons. Alternatively, the exuberant CS axons in $N p n-1$ mutant mice may form appropriate synapses with spinal interneurons, but the sheer overabundance of synaptic connections may disrupt the coordinated neural signaling required for the execution of skilled movements in the mutant mice. Finally, it is possible that the skilled motor deficits observed in Npn-1 mutant mice may actually be a result of the improper formation of other CS circuits, such as those in the dorsal spinal cord.

Sema3A has been shown to be critical for the formation of the dendrites in pyramidal neurons (Polleux et al., 2000; Gu et al., 2003; Tran et al., 2009), therefore, these dendrites may also be disrupted in Npn-1 mutant mice. Although some of the finer details remain to be determined about how Npn-1-Sema3A signaling brings about appropriate axon collateral formation, our genetic studies indicate that proper establishment of CS axon collaterals is critical for the development of skilled movements.

Interestingly, it has been shown that Sema3A is upregulated during injury (Lindholm et al., 2004). Thus, inhibiting this pathway after injury may be a potential strategy to promote axon collateral sprouting of surviving CSNs. Indeed, a Sema3A inhibitor has been shown to have a beneficial effect on axon regeneration and motor function recovery after spinal cord injury (Kaneko et al., 2006; Tohda and Kuboyama, 2011; Zhang et al., 2014). Because there are seven members of class 3 semaphorins in the mammalian genome (Tran et al., 2007), the inhibition of both neuropilin receptors (Npn-1 and Npn-2) represents a better approach to block all of the inhibitory cues elicited by this class of semaphorins to achieve better regeneration. As disrupted pat- 
terns of synaptic connectivity are also thought to underlie numerous developmental disorders (Gallo, 2011), it is our hope that broadening our understanding of the molecular mechanisms underlying axon collateral formation during normal development will yield new insights into therapeutic approaches for treating not only brain and spinal cord injuries, but also neurodevelopmental disorders involving aberrations in CS circuit development (Belmonte et al., 2004; Gallo, 2011; Lewis et al., 2013).

\section{References}

Asante CO, Chu A, Fisher M, Benson L, Beg A, Scheiffele P, Martin J (2010) Cortical control of adaptive locomotion in wild-type mice and mutant mice lacking the ephrin-eph effector protein alpha2-chimaerin. J Neurophysiol 104:3189-3202.

Bagnard D, Lohrum M, Uziel D, Püschel AW, Bolz J (1998) Semaphorins act as attractive and repulsive guidance signals during the development of cortical projections. Development 125:5043-5053.

Bareyre FM, Kerschensteiner M, Misgeld T, Sanes JR (2005) Transgenic labeling of the corticospinal tract for monitoring axonal responses to spinal cord injury. Nat Med 11:1355-1360.

Bastmeyer M, O'Leary DD (1996) Dynamics of target recognition by interstitial axon branching along developing cortical axons. J Neurosci 16: $1450-1459$.

Bechara A, Nawabi H, Moret F, Yaron A, weaver E, Bozon M, Abouzid K, Guan JL, Tessier-Lavigne M, Lemmon V, Castellani V (2008) FAKMAPK-dependent adhesion disassembly downstream of L1 contributes to semaphorin3A-induced collapse. EMBO J 27:1549-1562.

Behar O, Golden JA, Mashimo H, Schoen FJ, Fishman MC (1996) Semaphorin III is needed for normal patterning and growth of nerves, bones and heart. Nature 383:525-528.

Belmonte MK, Allen G, Beckel-Mitchener A, Boulanger LM, Carper RA, Webb SJ (2004) Autism and abnormal development of brain connectivity. J Neurosci 24:9228-9231.

Canty AJ, Murphy M (2008) Molecular mechanisms of axon guidance in the developing corticospinal tract. Prog Neurobiol 85:214-235.

Castellani V, Chédotal A, Schachner M, Faivre-Sarrailh C, Rougon G (2000) Analysis of the L1-deficient mouse phenotype reveals cross-talk between Sema3A and L1 signaling pathways in axonal guidance. Neuron 27:237249.

Castellani V, De Angelis E, Kenwrick S, Rougon G (2002) Cis and trans interactions of L1 with neuropilin-1 control axonal responses to semaphorin 3A. EMBO J 21:6348-6357.

Castellani V, Falk J, Rougon G (2004) Semaphorin3A-induced receptor endocytosis during axon guidance responses is mediated by L1 CAM. Mol Cell Neurosci 26:89-100.

Cheng HJ, Bagri A, Yaron A, Stein E, Pleasure SJ, Tessier-Lavigne M (2001) Plexin-A3 mediates semaphorin signaling and regulates the development of hippocampal axonal projections. Neuron 32:249-263.

Cohen NR, Taylor JS, Scott LB, Guillery RW, Soriano P, Furley AJ (1998) Errors in corticospinal axon guidance in mice lacking the neural cell adhesion molecule L1. Curr Biol 8:26-33.

Daily JL, Nash K, Jinwal U, Golde T, Rogers J, Peters MM, Burdine RD, Dickey C, Banko JL, Weeber EJ (2011) Adeno-associated virusmediated rescue of the cognitive defects in a mouse model for angelman syndrome. PloS One 6:e27221.

Dang P, Smythe E, Furley AJ (2012) TAG1 regulates the endocytic trafficking and signaling of the semaphorin3A receptor complex. J Neurosci 32: $10370-10382$

Ebert AM, Childs SJ, Hehr CL, Cechmanek PB, McFarlane S (2014) Sema6a and Plxna2 mediate spatially regulated repulsion within the developing eye to promote eye vesicle cohesion. Development 141:2473-2482.

Faulkner RL, Low LK, Liu XB, Coble J, Jones EG, Cheng HJ (2008) Dorsal turning of motor corticospinal axons at the pyramidal decussation requires Plexin signaling. Neural Dev 3:21.

Finger JH, Bronson RT, Harris B, Johnson K, Przyborski SA, Ackerman SL (2002) The netrin 1 receptors Unc5h3 and dcc are necessary at multiple choice points for the guidance of corticospinal tract axons. J Neurosci 22:10346-10356.

Gallo G (2011) The cytoskeletal and signaling mechanisms of axon collateral branching. Dev Neurobiol 71:201-220.

Gorski JA, Talley T, Qiu M, Puelles L, Rubenstein JL, Jones KR (2002) Cor- tical excitatory neurons and glia, but not GABAergic neurons, are produced in the Emx1-expressing lineage. J Neurosci 22:6309-6314.

Gu C, Rodriguez ER, Reimert DV, Shu T, Fritzsch B, Richards LJ, Kolodkin AL, Ginty DD (2003) Neuropilin-1 conveys semaphorin and VEGF signaling during neural and cardiovascular development. Dev Cell 5:45-57.

Gu Z, Kalambogias J, Yoshioka S, Han W, Li Z, Kawasawa YI, Pochareddy S, Li Z, Liu F, Xu X, Wijeratne HR, Ueno M, Blatz E, Salomone J, Kumanogoh A, Rasin MR, Gebelein B, Weirauch MT, Sestan N, Martin JH, Yoshida Y (2017a) Control of species-dependent cortico-motoneuronal connections underlying manual dexterity. Science 357:400-404.

Gu Z, Serradj N, Ueno M, Liang M, Li J, Baccei ML, Martin JH, Yoshida Y (2017b) Skilled movements require non-apoptotic bax/bak pathwaymediated corticospinal circuit reorganization. Neuron 94:626-641.e4.

Jakeman LB, Chen Y, Lucin KM, McTigue DM (2006) Mice lacking L1 cell adhesion molecule have deficits in locomotion and exhibit enhanced corticospinal tract sprouting following mild contusion injury to the spinal cord. Eur J Neurosci 23:1997-2011.

Kalil K, Dent EW (2014) Branch management: mechanisms of axon branching in the developing vertebrate CNS. Nat Rev Neurosci 15:7-18.

Kaneko S, Iwanami A, Nakamura M, Kishino A, Kikuchi K, Shibata S, Okano HJ, Ikegami T, Moriya A, Konishi O, Nakayama C, Kumagai K, Kimura T, Sato Y, Goshima Y, Taniguchi M, Ito M, He Z, Toyama Y, Okano H (2006) A selective Sema3A inhibitor enhances regenerative responses and functional recovery of the injured spinal cord. Nat Med 12:13801389.

Kitsukawa T, Shimizu M, Sanbo M, Hirata T, Taniguchi M, Bekku Y, Yagi T, Fujisawa H (1997) Neuropilin-semaphorin III/D-mediated chemorepulsive signals play a crucial role in peripheral nerve projection in mice. Neuron 19:995-1005.

Kullander K, Croll SD, Zimmer M, Pan L, McClain J, Hughes V, Zabski S, DeChiara TM, Klein R, Yancopoulos GD, Gale NW (2001) Ephrin-B3 is the midline barrier that prevents corticospinal tract axons from recrossing, allowing for unilateral motor control. Genes Dev 15:877-888.

Law CO, Kirby RJ, Aghamohammadzadeh S, Furley AJ (2008) The neural adhesion molecule TAG-1 modulates responses of sensory axons to diffusible guidance signals. Development 135:2361-2371.

Lemon RN (2008) Descending pathways in motor control. Annu Rev Neurosci 31:195-218.

Lewis TL Jr, Courchet J, Polleux F (2013) Cell biology in neuroscience: cellular and molecular mechanisms underlying axon formation, growth, and branching. J Cell Biol 202:837-848.

Lindholm T, Sköld MK, Suneson A, Carlstedt T, Cullheim S, Risling M (2004) Semaphorin and neuropilin expression in motoneurons after intraspinal motoneuron axotomy. Neuroreport 15:649-654.

Liu Y, Shi J, Lu CC, Wang ZB, Lyuksyutova AI, Song XJ, Zou Y (2012) Ryk-mediated Wnt repulsion regulates posterior-directed growth of corticospinal tract. Nat Neurosci 8:1151-1159.

Luong TN, Carlisle HJ, Southwell A, Patterson PH (2011) Assessment of motor balance and coordination in mice using the balance beam. J Vis Exp 49:e2376.

Maione F, Molla F, Meda C, Latini R, Zentilin L, Giacca M, Seano G, Serini G, Bussolino F, Giraudo E (2009) Semaphorin 3A is an endogenous angiogenesis inhibitor that blocks tumor growth and normalizes tumor vasculature in transgenic mouse models. J Clin Invest 119:3356-3372.

Martin JH (2005) The corticospinal system: from development to motor control. Neuroscientist 11:161-173.

Nakamura T, Colbert MC, Robbins J (2006) Neural crest cells retain multipotential characteristics in the developing valves and label the cardiac conduction system. Circ Res 98:1547-1554.

Paixão S, Balijepalli A, Serradj N, Niu J, Luo W, Martin JH, Klein R (2013) EphrinB3/EphA4-mediated guidance of ascending and descending spinal tracts. Neuron 80:1407-1420.

Polleux F, Morrow T, Ghosh A (2000) Semaphorin 3A is a chemoattractant for cortical apical dendrites. Nature 404:567-573.

Porter R, Lemon R (1993) Corticospinal function and voluntary movement. Oxford, UK; New York: Clarendon; Oxford UP.

Raper JA (2000) Semaphorins and their receptors in vertebrates and invertebrates. Curr Opin Neurobiol 10:88-94.

Rünker AE, Little GE, Suto F, Fujisawa H, Mitchell KJ (2008) Semaphorin-6A controls guidance of corticospinal tract axons at multiple choice points. Neural Dev 3:34.

Schaeren-Wiemers N, Gerfin-Moser A (1993) A single protocol to detect 
transcripts of various types and expression levels in neural tissue and cultured cells: in situ hybridization using Digoxigenin-labelled cRNA probes. Histochemistry 100:431-440.

Sibbe M, Taniguchi M, Schachner M, Bartsch U (2007) Development of the corticospinal tract in Semaphorin3A- and CD24-deficient mice. Neuroscience 150:898-904.

Starkey ML, Barritt AW, Yip PK, Davies M, Hamers FP, McMahon SB, Bradbury EJ (2005) Assessing behavioural function following a pyramidotomy lesion of the corticospinal tract in adult mice. Exp Neurol 195:524-539.

Sun LO, Brady CM, Cahill H, Al-Khindi T, Sakuta H, Dhande OS, Noda M, Huberman AD, Nathans J, Kolodkin AL (2015) Functional assembly of accessory optic system circuitry critical for compensatory eye movements. Neuron 86:971-984.

Suto F, Tsuboi M, Kamiya H, Mizuno H, Kiyama Y, Komai S, Shimizu M, Sanbo M, Yagi T, Hiromi Y, Chédotal A, Mitchell KJ, Manabe T, Fujisawa $\mathrm{H}$ (2007) Interactions between plexin-A2, plexin-A4, and semaphorin $6 \mathrm{~A}$ control lamina-restricted projection of hippocampal mossy fibers. Neuron 53:535-547.

Taniguchi M, Yuasa S, Fujisawa H, Naruse I, Saga S, Mishina M, Yagi T (1997) Disruption of semaphorin III/D gene causes severe abnormality in peripheral nerve projection. Neuron 19:519-530.

Tohda C, Kuboyama T (2011) Current and future therapeutic strategies for functional repair of spinal cord injury. Pharmacol Ther 132:57-71.

Tran TS, Kolodkin AL, Bharadwaj R (2007) Semaphorin regulation of cellular morphology. Annu Rev Cell Dev Biol 23:263-292.

Tran TS, Rubio ME, Clem RL, Johnson D, Case L, Tessier-Lavigne M, Huganir RL, Ginty DD, Kolodkin AL (2009) Secreted semaphorins con- trol spine distribution and morphogenesis in the postnatal CNS. Nature 462:1065-1069.

Ueno M, Nakamura Y, Li J, Gu Z, Niehaus J, Maezawa M, Crone SA, Goulding M, Baccei ML, Yoshida Y (2018) Corticospinal circuits from the sensory and motor cortices differentially regulate skilled movements through distinct spinal interneurons. Cell Rep 23:1286-1300.e7.

Wegmeyer H, Egea J, Rabe N, Gezelius H, Filosa A, Enjin A, Varoqueaux F, Deininger K, Schnütgen F, Brose N, Klein R, Kullander K, Betz A (2007) EphA4-dependent axon guidance is mediated by the RacGAP alpha2chimaerin. Neuron 55:756-767.

Xu T, Yu X, Perlik AJ, Tobin WF, Zweig JA, Tennant K, Jones T, Zuo Y (2009) Rapid formation and selective stabilization of synapses for enduring motor memories. Nature 462:915-919.

Yaron A, Huang PH, Cheng HJ, Tessier-Lavigne M (2005) Differential requirement for plexin-A3 and -A4 in mediating responses of sensory and sympathetic neurons to distinct class 3 semaphorins. Neuron 45:513-523.

Yoshida Y, Han B, Mendelsohn M, Jessell TM (2006) PlexinAl signaling directs the segregation of proprioceptive sensory axons in the developing spinal cord. Neuron 52:775-788.

Z'Graggen WJ, Metz GA, Kartje GL, Thallmair M, Schwab ME (1998) Functional recovery and enhanced corticofugal plasticity after unilateral pyramidal tract lesion and blockade of myelin-associated neurite growth inhibitors in adult rats. J Neurosci 18:4744-4757.

Zhang L, Kaneko S, Kikuchi K, Sano A, Maeda M, Kishino A, Shibata S, Mukaino M, Toyama Y, Liu M, Kimura T, Okano H1, Nakamura M (2014) Rewiring of regenerated axons by combining treadmill training with semaphorin3A inhibition. Mol Brain 7:14. 